\title{
DSRP Theory: A Primer
}

\author{
Derek Cabrera $^{1,2, *,+(\mathbb{C})}$ and Laura Cabrera ${ }^{1,2,+}$
}

1 Jeb E. Brooks School of Public Policy, Cornell Institute for Public Affairs, SC Johnson College of Business, Cornell University, Ithaca, NY 14850, USA; lac19@cornell.edu

2 Cabrera Research Lab, Ithaca, NY 14850, USA

* Correspondence: dac66@cornell.edu

+ These authors contributed equally to this work.

\begin{abstract}
DSRP Theory is now over 25 years old with more empirical evidence supporting it than any other systems thinking framework. Yet, it is often misunderstood and described in ways that are inaccurate. DSRP Theory describes four patterns and their underlying elements-identity $(i)$ and other $(o)$ for Distinctions $(D)$, part $(p)$ and whole $(w)$ for Systems $(S)$, action $(a)$ and reaction $(r)$ for Relationships $(R)$, and point $(\rho)$ and view $(v)$ for Perspectives $(P)$ - that are universal in both cognitive complexity (mind) and material complexity (nature). DSRP Theory provides a basis for systems thinking or cognitive complexity as well as material complexity (systems science). This paper, as a relatively short primer on the theory, provides clarity to those wanting to understand DSRP and its implications.
\end{abstract}

Keywords: DSRP theory; universals; cognitive complexity; systems thinking; complexity; systems science; structural predictions; organization of information

\section{Introduction: DSRP Theory}

DSRP Theory (DSRP stands for Distinctions, Systems, Relationships, Perspectives) describes four patterns and their underlying elements: identity $(i)$ and other $(o)$ for Distinctions $(D)$, part $(p)$ and whole $(w)$ for Systems $(S)$, action $(a)$ and reaction $(r)$ for Relationships $(R)$, and point $(\rho)$ and view $(v)$ for Perspectives $(P)$. The four patterns and their eight, base-paired, co-implying elements do not draw on the dictionary for their definitions. Instead they are equivalencies in which each pattern has the same structure given as: A pattern is defined as element $t_{1}$ co-implying element $2\left(\mathbb{P} \equiv e_{1} \Leftrightarrow e_{2}\right)$. Thus the four rules of DSRP Theory are:

Received: 10 December 2021

Accepted: 14 February 2022

Published: 2 March 2022

Publisher's Note: MDPI stays neutral with regard to jurisdictional claims in published maps and institutional affiliations.

Copyright: ๑) 2022 by the authors. Licensee MDPI, Basel, Switzerland. This article is an open access article distributed under the terms and conditions of the Creative Commons Attribution (CC BY) license (https:// creativecommons.org/licenses/by/ $4.0 /)$.

- Distinction is defined as identity co-implying other $(D \equiv i \Leftrightarrow 0)$.

- System is defined as part co-implying whole $(S \equiv p \Leftrightarrow w)$.

- Relationship is defined as action co-implying reaction $(R \equiv a \Leftrightarrow r)$.

- Perspective is defined as point co-implying view $(P \equiv \rho \Leftrightarrow v)$.

These simple rules, much like the simple rules of games like chess or go, result in an unexpected amount of complexity. Seemingly mundane or pedestrian rules can "roll up" to create surprising results (i.e., emergent properties, system behavior, etc.). For example, change the simple rule of what a queen or a rook can or cannot do in the game of chess, and the complexity and possibilities of the game also change dramatically. For example, allowing a pawn to go backward or to "take" forward would change the game. Limiting a queen from diagonal movement would change the game dramatically. There can be a near infinite amount of variety in the game of chess or in a given instantiation of a chess game, but the rules of how the agents move and relate are the universals that "roll up" into all that diversity. Similarly, the four DSRP rules result in the complexity of human thought, "systems thinking" or cognitive complexity. Awareness of these four rules-called metacognition-allows the user to make structural predictions based on two additional rules that emerge out of DSRP's dynamics. 
DSRP Theory explains that four patterns organize information to create meaning about what exists and what we perceive. The simplest accurate statement of DSRP Theory is thus:

\begin{tabular}{|c|c|c|c|c|c|}
\hline & & that which is Organized & & Distinctions & Systems \\
\hline "the & $\begin{array}{l}\text { Ways } \\
\text { Relatii }\end{array}$ & information & is/is & $\begin{array}{c}\text { not bounded, } \\
\text { Perspectives }\end{array}$ & arranged, \\
\hline anc & $\begin{array}{l}\text { interco } \\
\text { al Complexity }\end{array}$ & $\underset{\text { (Nature) }}{\text { nnected from }}$ & fram & $\begin{array}{l}\text { es of reference } \\
\text { omplexity (Mind) }\end{array}$ & determines \\
\hline
\end{tabular}

DSRP Theory details quite a bit more than this simplification relays [1-6]. In addition, as pointed out in Cabrera, Cabrera, and Midgley [7] in a discussion of how DSRP Theory has brought about a fourth wave in systems thinking, the authors write:

Since Cabrera's first writings, we now have the benefit of over 20 years of hindsight on the possible start of a fourth wave (which is as long as the gap between the first and second waves, and twice as long as the gap between the second and third waves). During those years, we have seen considerable testing of Cabrera's DSRP Theory, including: (1) a burgeoning amount of empirical evidence (at least as much as has been offered in the previous waves); (2) substantial private sector funding to develop tools for systems thinking; (3) substantial public funding for research; (4) a substantial peer review and publication history, sizeable citation histories, including several special issues dedicated to DSRP; (5) considerable public exposure and critique; (6) public adoption; (7) high attendance annual conferences; institutional recognition and support; and (9) as yet, few competitor theories (at least, none that have been explicated and communicated to the same degree).

In short, in the 25 years since its discovery [8,9], DSRP Theory has more empirical evidence supporting it than any existing "systems theory" [6,7,10-17]. The term theory is used loosely here as it is in the field writ large. Most of what exists in the field are opinioned, mostly unvalidated frameworks. These frameworks-many that have been around for some time and are popular-are not "theories" like DSRP is, because a theory requires an accumulation of evidence. It should be further noted that establishing an accumulation of evidence for a theory requires both basic (existential) and applied (efficacy) research. To our knowledge, none of the existing frameworks for systems thinking have basic empirical evidence for their existence. In rare cases, there are efficacy studies which is a positive sign, but not a replacement for basic research that shows the existence of such claims. DSRP Theory sits within this wider comparative context of systems thinking frameworks that are sometimes mislabelled as theories. The systems thinking "universe" includes thousands of frameworks which Cabrera [6] explains capture the systems thinking and systems science universe, what he called in 2006 the "MFS universe" (named after these three authors).

Midgley, Francois and Schwarz-have made separate attempts to encapsulate the long history and vast terrain of knowledge-about-systems. Midgley acted as editor to the most complete review of systems thinking available today. Midgley's four-volume collection, entitled Systems Thinking [18], includes ninetyseven papers that he and an International Advisory Board of "forty-seven distinguished writers from across the spectrum of the systems movement" (p5) thought were seminal... Francois assembled the two-volume International Encyclopedia of Systems and Cybernetics [19], which contains 3800 distinct systems concepts... Schwarz [20] developed a map entitled "Some Streams of Systemic Thought" with over 1000 nodes.

This universe includes a vast history of systems ideas from Lao Tsu to the Santa Fe Institute (SFI). Some of these ideas relate specifically to systems thinking. Additionally, within this subset of ideas a few notable frameworks have been proposed, some of the 
most popular and enduring include: System Dynamics (SD), Soft Systems Methodology (SSM), Critical Systems Thinking (CST), and General Systems Theory (GST). Yet, while these theories have been substantively generative in terms of academic debate, dialogue, and even publication (to our knowledge) none have accumulated evidence of their existence as phenomena. If their premises, postulates, or principles are to stand as anything more than opinion, these premises must be tested empirically. Additionally, these empirical tests must go beyond the initial stages of efficacy and case studies with small sample sizes. Simply put, these frameworks have been around long enough to expect as much. This is not to say that the debate on DSRP Theory is closed-in science it never is. However, there is accumulating evidence in a relatively short period of time. Whereas, for these other frameworks, which have had substantively more time, there is little accumulated evidence that shows they are anything more than opinions supported by a tribe. In other words, if SD, SSM, GST, or CST are proffered frameworks of systems thinking, then where is the empirical data that shows they are real-world phenomena? This is especially the case when one differentiates between existential (basic research) and efficacy (applied research) studies, where the former is far less often available. Whereas DSRP Theory is relatively new, these frameworks have been around for a long time. One would expect that this accumulation of empirical evidence would be readily available, yet it is not. Jackson's CST for example, has been around 40 years [21] yet in his recent book that summarizes his work, he provides just three qualitative case studies with small samples. No experimental studies. Of course, an absence of evidence is not evidence of absence, but it is a lack of evidence. These frameworks, which have been masquerading as theories of systems thinking are not theories, because they have not accumulated empirical evidence. Yet, they maintain an elevated status in the field. CST, with its unsupported claim for the efficacy of methodological pluralism and anti-universality leanings, maintains an innovation-killing stranglehold on the field. Unsupported by substantive empirical evidence, but with an abundance of straw-man tactics, the CST establishment detracts from empirically supported theories with the field's dominant dog-whistle: accusations of reductionism. For universality, it uses straw-man tactics. For example, Jackson [22] dismisses DSRP Theory with a simplistic straw-man when he writes, "A classic attempt is that of Cabrera et al. (2015) who use four underlying "rules" — distinctions, systems, relationships, and perspectives (DSRP) - to unify and organize the field of systems thinking. These concepts mean different things according to the paradigm in which they are located. CST just has to learn to live with and manage paradigm incommensurability." Jackson seems to believe that if terminology differs in its definitions (which it always does) then the theory is invalid, as if theory is validated by the commensurability of semantics. However, DSRP Theory is not simply "four words" any more than the theory of relativity is simply what people mean when they say energy, mass, and constant. The four DSRP words are representative of a complex set of structures and equivalencies. Translated into French, or Swahili, for example, would not threaten the underlying formalisms and predictions of DSRP.

Some of the terminology and concepts of DSRP Theory have been discussed back to antiquity (part-whole, for example). However, we hope the reader will see-as a result of this primer-that DSRP Theory is far more specific, predictive, and empirically testable than are these shared basic terminology or general concepts. DSRP Theory makes very specific predictions about the world. It is not merely a compilation, but a specific description of how things work and predictably how they will work. The reader who takes DSRP's terminology on its face as being "old hat" will miss the specific predictions DSRP makes possible and its broader applications and implications. To argue, as some have, that DSRP is just a rehash of General Systems Theory (GST) is parcel of why this primer is needed. This primer spells out in certain, specific, and mathematical precision what DSRP Theory states and the predictions it makes. Nowhere in GST is such specificity offered. Merely using some of the same terminology (e.g., parts, wholes, relationships, etc.) is not enough.

DSRP Theory explicates the underlying simple rules of organization for both material and cognitive complexity. It states that these rules are universal, mutually exclusive, and 
collectively exhaustive and that they operate in parallel. DSRP Theory makes specific, organizational, structural, predictions that can be tested.

For more on DSRP Theory proper, the reader should see the many citations provided herein, several of which include full literature reviews that involve hundreds of empirical studies. DSRP Theory provides the underlying rule structure for the complex adaptive system that yields the emergent property we call systems thinking (or increased cognitive complexity) as well as material complexity.

\section{Empirical Findings of DSRP across the Disciplines}

There is an abundance of interest, literature, and empirical findings on DSRP patterns across the disciplinary spectrum (i.e., the physical, natural, social and applied sciences). The literature on distinction making [23-57] and boundary judgments is well established, both in the cognitive sciences and the field of systems thinking. In the cognitive sciences (as well as the physical and natural sciences) it is clear that distinction making is existent [24-27,29-31]. In a review of literature, empirical studies illustrate both the universality of identity-other Distinctions across the disciplines [23-31,33-42,44-61] and that Distinctions are integrated with other universals (Systems, Relationships, Perspectives) [43,62-94].

The literature on part-whole Systems [6,25,95-109] (a.k.a., grouping, sorting, categorization, organization, etc.) is well established, both in the cognitive sciences and systems thinking contexts. In the cognitive sciences (as well as the physical and natural sciences) it is clear that part-whole Systems are ever present [97-99,101,105,107,108]. In systems thinking literature, categorization has been said to be, “(...) predicted from the structure of the environment at least as well as it can from the structure of the mind" [97]. While categorization is more limited than part-whole Systems, the research done on categorization $[53,54,77-79,81,83,85,91,97-99,106-108,110]$ has shown the fundamental existence of the Systems rule. It is not new that categories are made through sorting parts into wholes, but what is new is that categories also imply a perspective, integrating the part-whole Systems rule into the rest of the DSRP theory. This critical insight-part of DSRP Theory-exposes the universality of part-whole systems at the theoretical level. In a review of literature, a number of empirical studies illustrate the universality of part-whole Systems across the disciplines [25,96-109] and part-whole Systems integrated with other universals (Distinctions, Relationships, Perspectives) [43,62,64-94].

The literature on Relationships [110-124] is also well established in both the cognitive sciences and systems thinking contexts. In the cognitive sciences (as well as the physical and natural sciences) it is clear that relationships are ever present $[114,118,119,121,123]$. Causality (a term that refers to phenomena that is a subset of action-reaction Relationships) has been shown to be present in children [114,119-121,124], adults, and can be utilized as, "(...) a tool for gaining deeper understanding" [123]. Cabrera [6] expanded the definition of Relationships by demonstrating that: (1) all relational processes were cases of relationships between an action and a reaction variable and (2) that action-reaction relationships were not reserved merely for the systems' cause and effects alone, but were structural features occurring on fractal dimensions. This critical insight-part of DSRP Theory-exposed the universality of action-reaction Relationships at the theoretical level. This study empirically quantifies this theoretical construct. In a 2021 [16] review of literature, a number of empirical studies illustrate the universality of action-reaction Relationships across the disciplines [25,110-124]. It is also clear that Relationships are not enough. That they are necessary but not sufficient to explain an underlying, universal, structural grammar of cognition or to navigate the complexities of real-world systems. Empirical findings from the literature also reveal what DSRP Theory predicts: that action-reaction Relationships are integral with other universals (i.e., Distinctions, Systems, Perspectives) [43,62,64-94].

Perspective is one of the most important aspects of human cognition, given our status as social animals. In a literature review of perspective taking [16] a number of empirical studies show the universality of perspectives across the disciplines [125-157]. In the cognitive sciences (as well as the physical and natural sciences) it is clear that perspectives 
are ever present $[126,128-132,134,136,137,139,142,154]$. It is also clear that perspectives are not enough. That they are necessary but not sufficient to explain an underlying, universal, structural grammar of cognition. Empirical findings from the literature also reveal what DSRP Theory predicts: that point-view Perspective is integral with other universals (i.e., Distinctions, Systems, Relationships) [43,62,64-94].

\section{Research Methods}

Fundamentally, DSRP Theory is a formal description of the universals of organization or the patterns that connect all knowledge (a.k.a., consilience). At its core, DSRP Theory asks the fundamental question: how are things organized in both mind and nature? An accumulation of research that supports DSRP Theory answers the research questions shown in Table 1.

Table 1. Research questions for DSRP Theory.

\begin{tabular}{|c|c|c|}
\hline \multirow[b]{2}{*}{$\begin{array}{c}\text { Mind } \\
\text { (cognitive complexity) }\end{array}$} & $\begin{array}{c}\text { Existential } \\
\text { (Basic Research) }\end{array}$ & $\begin{array}{c}\text { Efficacy } \\
\text { (Applied Research) }\end{array}$ \\
\hline & $\begin{array}{c}\text { Does DSRP Exist in } \\
\text { Mind? } \\
\text { (i.e., Does DSRP exist as } \\
\text { universal, material, } \\
\text { observable cognitive } \\
\text { phenomena?) }\end{array}$ & \multirow{2}{*}{$\begin{array}{c}\text { Is Metacognitive } \\
\text { Awareness of DSRP } \\
\text { Effective? } \\
\text { (i.e., Does it increase ability to } \\
\text { align cognitive complexity to } \\
\text { real-world complexity?) (a.k.a., } \\
\text { parallelism) }\end{array}$} \\
\hline \multirow[t]{2}{*}{$\begin{array}{c}\text { Nature } \\
\text { (material complexity) }\end{array}$} & $\begin{array}{c}\text { Does DSRP Exist in } \\
\text { Nature? } \\
\text { (i.e., Does DSRP exist as } \\
\text { universal, material, } \\
\text { observable phenomena?) }\end{array}$ & \\
\hline & \multicolumn{2}{|c|}{ EMPIRICAL BASIS } \\
\hline
\end{tabular}

Basic research investigates the existence and universality of DSRP in mind/nature whereas applied research investigates the efficacy (defined as the effect of metacognitive awareness of DSRP) and parallelism (defined as the probability that organizational rules of mind align with organizational rules of nature), both of which are central to the idea of the Systems Thinking/DSRP Loop in Figure 1, which shows that DSRP-Systems Thinking fits mental models to real-world observables and feedback. It should be noted that the ST/DSRP Loop is the mirror opposite of confirmation bias. Confirmation bias reverses this loop, by fitting reality to one's mental models. Parallelism is therefore the degree to which one's cognitive paradigm, style, or mindset, aligns with nature's.

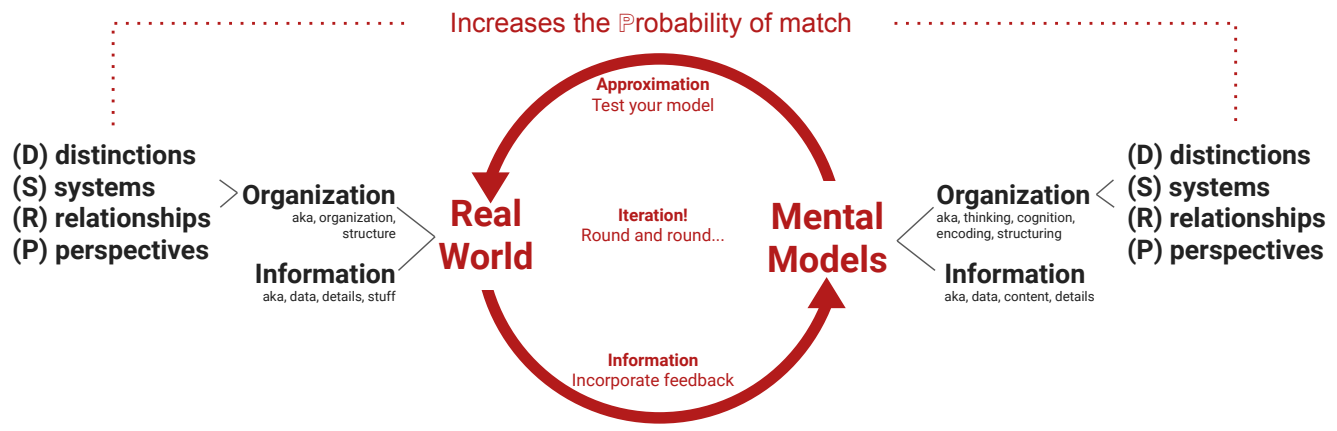

Figure 1. The ST/DSRP Loop. 
DSRP Theory articulates the universal structures and dynamics for organizing $(\mathbb{O})$ information $(\mathbb{I})$. Both in the mind, as part of mental models $(\mathbb{M})$ - defined as the complex product of information and DSRP thinking $(\mathbb{M}=\mathbb{I} \otimes \mathbb{T})$ - but also as part of reality $(\mathbb{R})$ - defined as the complex product of information and DSRP organization $(\mathbb{R}=\mathbb{I} \otimes \mathbb{O}$ ) - where both $\mathbb{O}$ and $\mathbb{T}=D S R P$, and the hat symbol $(\hat{x})$ is used to denote the sample or sampling of information and structure, as shown in Equation (1). It should be noted that different symbols are sometimes used for organization $(\mathbb{O})$ to differentiate thought-based organization (where $\mathbb{T}$ is used for "thinking") versus more general organization (where $\mathbb{O}$ is used) of information as is the case for energy and matter (that information is a basic property of the universe is well trodden [158-163]. Thus, $\mathbb{T}=\hat{\mathbb{O}}=D S R P$. Thus, the goal of systems thinking is to increase the value of the fraction between our mental models and reality such that $\frac{\mathbb{M}}{\mathbb{R}}=1$. The relationship between mental models and reality is a fraction because our mental models - quite literally-represent only a fraction of what exists. Incidentally, $\frac{\mathbb{M}}{\mathbb{R}}=1$ need not be bounded by 1 other than that the number 1 represents unity as in $\frac{\mathbb{X}}{\mathbb{X}}=1$. It could therefore equal any number over itself. This is an aspirational goal. However, interestingly, it is this aspirational goal that differentiates the phenomenon of systems thinking from plain-old thinking. Because systems thinking has an expressed aspirational goal of making the fraction between mental models $(\mathbb{M})$ and reality $(\mathbb{R})$ equal to 1 , such that $\frac{\mathbb{M}}{\mathbb{R}}=\frac{1}{1}=1$. Thinking does not have this aspirational goal, so it does not require metacognition (just cognition). Otherwise, they are exactly the same. However that is a pretty big otherwise. The formalism for DSRP is detailed and explained in Equation (1):

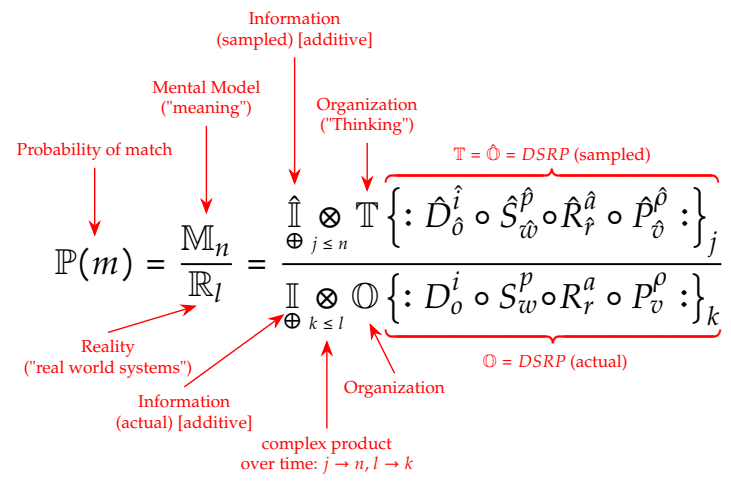

A simple way to understand this formula is to focus in on just one portion of the fraction between mental models and reality: $\frac{\mathbb{M}}{\mathbb{R}}$. We will use the $\frac{\hat{S}_{w}^{\hat{p}}}{S_{w}^{p}}$ by asking about your mental model of the parts of an ecology versus the actual parts of an ecology. Your mental model might include 247 parts whereas you estimate that the actual ecology includes many more than 247 parts $(\gg 247)$. Thus, $\frac{\hat{S}_{\hat{p}}^{\hat{p}}}{S_{w}^{p}}=\frac{247}{\gg 247}=2.47 \times 10^{-M}=2.47 \mathrm{e}-M$ (i.e., scientific notation a very small number). The astute reader may recognize that mental models filter reality but could also amplify it. Nevertheless, this amplification becomes part of reality, even if it is invalid or "wrong" as is often the case with perspective. For example, many people believe the COVID-19 is a hoax. This perspective in and of itself has no validity, yet this invalid perspective drives agent behavior that manifests empirically in the system. If your understanding of those $2.47 \mathrm{e}-M$ parts is useful in whatever it is you are trying to accomplish in the ecology, then the numerator (your mental model) suffices as a model for the denominator (reality). If it does not then you might make the structural prediction that there are more/different parts that you need to understand. Regardless, because (1) the denominator is almost always effectively much greater than the numerator, and (2) all signal from reality is filtered through our mental models, the formula above can be summarized to: 


$$
\begin{aligned}
& \mathbb{M}=\mathbb{I} \otimes \mathbb{T} \\
& \text { where, } \\
& \mathbb{T}=\hat{\mathbb{O}}=D S R P
\end{aligned}
$$

In other words, our mental models are built on meaningfully organizing information with DSRP. The formalism for DSRP Theory clarifies a number of important things:

1. the applicable domains (reality (or real-world systems) and mental models);

2. the goal (increasing the probability. Regarding $\frac{\mathbb{M}}{\mathbb{R}}=1$, the evidence that DSRP Theory increases this probability-what we call parallelism-is that we see DSRP in both material (empirical) complexity and cognitive complexity (see [6,7,10-17,164]). Note that (a) the fraction, $\frac{\mathbb{M}}{\mathbb{R}}=1$, is not the same as the probability that this fraction is closer to 1 ; (b) the closer it gets to 1 the more accurate the mental model; (c) evidence for the validity of a specific mental model $(X)$ is not the same as evidence for this increased probability. These are sometimes confused as a match between mental models and reality (a.k.a., parallelism);

3. the universal structures and structural rules of organization (i.e., DSRP);

4. the dynamical rules (co-implication and simultaneity);

5. the fundamental action (organization, or $\mathbb{O}$ );

6. the fundamental element being acted upon or organized (i.e., information, or $\mathbb{I}$ );

7. the relationship between information and organization over time (complex product, or $\otimes)$;

8. the basis on which to make structural predictions that aid knowledge creation, innovation, invention and discovery.

This last item-structural predictions - represents the most important contribution of DSRP Theory: it lets us make predictions about highly probable structures in our thinking and then "fill in" these structures with informational variables (a.k.a., discovery at the personal, professional, social, or scientific scales). To understand where structural predictions come from, we must understand the co-implication and simultaneity rules. To do that, we travel a logical path, akin to Aristotle's Law of the Excluded Middle, but without excluding the middle (thus nesting bivalent logic within multivalent or DSRP logic) [43]. The logic, explained in the following steps, explicates how in order for any "thing" to exist (call it $A$ ), DSRP structure is necessary.

Table 2 provides the basic logic of DSRP explained in visual form. It may seem more abstract or esoteric than it really is. However, what is being described aids in the invention of basic systems mapping software like Plectica or network analysis where a single information variable acts as several different structures simultaneously. In Figure 2, for example, you can see that the node labeled US Ambassador to China is an identity, with a specific, articulated point of view on several items in the map (all the blue dots), and, a part of several larger wholes including being one part of a diplomatic relationship between the US and China. Simultaneously, the US Ambassador is engaged in an interpersonal relationship with the Chinese Ambassador which is, in turn, part of a larger system of relationships. All of the various nodes in this system (even the inanimate ones) may have a perspective on some Global Issue X.

Figure 2 shows - using a simple example-how D, S, R, and P occur simultaneously and not as separate "buckets" or "categories". D, S, R, and P are dynamical simple rules of interaction where, for example, a single relationship (R) can be distinguished (D), and systematized (S), from a perspective $(\mathrm{P})$. These rules can be iterated for any bit of information. 

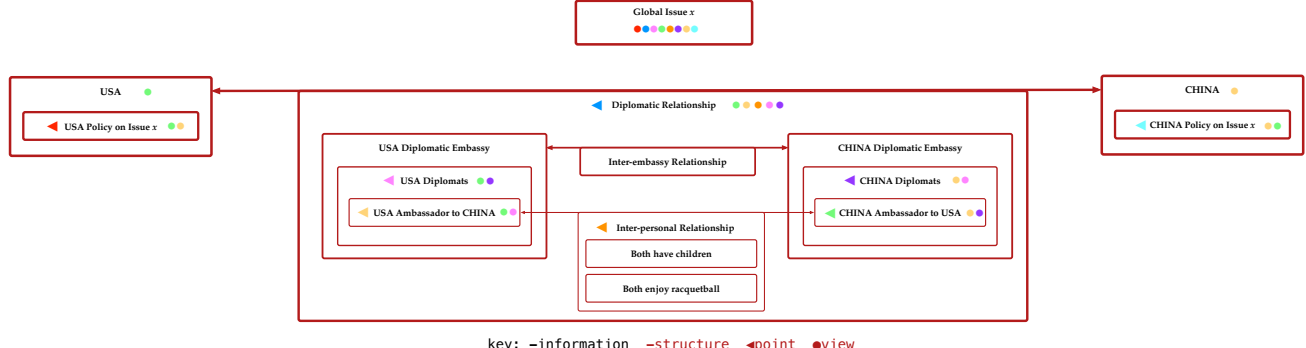

Figure 2. DSRP logic in practice.

Table 2. Derivation of DSRP rules: logic and definitions.

Logic Step
If an identity $(i)$ exists, it implies an other $(o)$.
Therefore, Distinctions $\left(D_{o}^{i}\right)$ exist, universally.

\section{Results In Practice}

DSRP Theory explicates all of these facets of reality and of our mental models of reality with the hopes of getting them in better alignment. We will start with the steps in Table 2. The origin of DSRP starts with any identity - e.g., any concept or thing. The logical conclusion of DSRP Theory is simple: the existence of " $\mathrm{A}$ " implies DSRP. Let us see how this simple conclusion is derived. In Step (1) of Table 2, if an identity (i) structure exists, that we will informationally call " $A$ ". Then by definition an other $(o)$ structure also exists that we can call " $\neg A$ ". This means that if $A$ exists (and $A$ represents anything) then an identity-other Distinction $\left(D_{o}^{i}\right)$ must also exist.

In Step (2) of Table 2, it follows that if $A$ co-implies $\neg A$, then there is, by definition, a Relationship (R) between them, in which an $A$-like action $\left(\vec{A}_{a}\right)$ has an $\neg A$-like reaction $\left(\neg \vec{A}_{r}\right)$. Vice versa, an $\neg A$-like action $\left(\neg \overleftarrow{A}_{a}\right)$ has an A-like reaction $\left(\overleftarrow{A}_{r}\right)$. Note that these action-reaction variables are themselves identities $(i)$ and they are also others $(o)$. This means that if $A$ (i.e., anything) exists then an action-reaction Relationship $\left(R_{r}^{a}\right)$ must also exist.

In Step (3) of Table 2, we see that when $>1$ identities are related, a System (S) exists in which all of the elements $(\mathrm{A}, \neg A$, and their action-reaction variables) of the system are 
parts $(p)$ of the whole $(w)$. Ergo, a whole $(w)$ must also exist. This whole we can call "A/ $\neg A$ " and it is also an identity $(i)$. An other $(o)$ therefore exists, ad infinitum... This means that if $A$ (i.e., anything) exists then a part-whole System $\left(S_{w}^{p}\right)$ must also exist. Importantly, DSRP Theory treats both structural parts and relational parts, as parts of the whole.

In Step (4) of Table 2, we see that the original (in Step (1)) system was defined entirely in terms of A. This means the frame of reference (a.k.a., Perspective $(\mathrm{P})$ ) is from the pointof-view of $A$, such that everything in the system is defined in terms of $A$, such as $\neg A$. However, $\neg A$ is not merely defined in terms of $A$, it could also be defined on its own terms, let us call it $B$. Thus, we could as easily have started with $B$, and defined the system in terms of $B$ such that $B$ is the point $(\rho)$ and $\neg B$ is the view (v). In this case, $\neg A=B$ and therefore, taking both perspectives at once, that $\mathrm{A}$ and $\neg A$ and $\mathrm{B}$ and $\neg B$ can simultaneously be identity $(i)$, other $(o)$, point $(\rho)$, or view $(v)$. In fact, all identities $(i)$ can simultaneously be all of the element variables: identity $(i)$, other $(o)$, part $(p)$, whole $(w)$, action $(a)$, reaction $(r)$, point $(\rho)$, or view $(v)$. Thus, all patterns (DSRP) are co-implying coupled oscillators and their eight elements are simultaneously exciting and inhibiting. This means that if $A$ (i.e., anything) exists then a point-view Perspective $\left(P_{v}^{\rho}\right)$ must also exist. We see that the entire system is the same from a different perspective: from $B$, which we originally defined in terms of $\mathrm{A}$ as not-A. Thus, in the image in Step (3) in Table 2, $\mathrm{B}$ is a function of $\mathrm{A}(B=B(A))$ whereas in the image in Step (4), $\mathrm{A}$ is a function of $\mathrm{B}(A=A(B))$. Thus, $B=\neg A$ and $A=\neg B$.

In Step (5) we arrive at the conclusion that in order for A to exist, D, S, R, and P must also exist (as well as their respective elements).

While Table 2 provides the basic steps explained in visual symbolic logic, the symbolic logic shown in Equation (3) through (8) highlights the simultaneity rule because it shows that of a single bit of information (blue) can act in several structural capacities (red). For example, Equation (3) shows that some bit of information can simultaneously take on some (in bold) or all of a matrix of the eight elemental structures $i, o, p, w, a, r, \rho, v$.

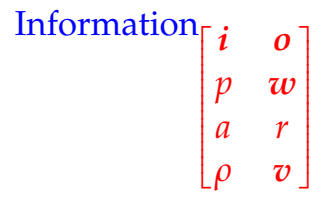

Equation (4) shows the same idea shown in Step (1) in Table 2: that if an identity ( $i$ ) called $A$ exists $(\exists)$, it is co-implied $(\Leftrightarrow)$ that an other $(o), \neg A$ exists and vice versa (red indicates universal DSRP elements and the blue represents the information variables). This means that if $A$ exists (and $A$ represents anything) then an identity-other Distinction $\left(D_{o}^{i}\right)$ must also exist.

$$
\begin{gathered}
\exists A_{i} \stackrel{\text { implies }}{\Longrightarrow} \exists \neg A_{O} \\
\exists \neg A_{o} \stackrel{\text { implies }}{\Longrightarrow} \exists A_{i}
\end{gathered}
$$

Therefore:

$$
\exists A_{i} \stackrel{\text { co-implies }}{\Longleftrightarrow} \exists \neg A_{O}
$$

If, according to Equation (4), $A$ co-implies $\neg A$, then there is, by definition, a Relationship (R) between them. In Step (2) of Figure 2, this Relationship (R) is illustrated. Using color in Equation (5), we see that the Relationship is not only a structure or "thing" in and of itself, it also has structural parts (actions-reactions). The specific action-reaction parts of a Relationship (R) are often hidden when we describe it in words. For example, we might say that there is a relationship between a small and large circle $(\circ \bigcirc)$ : one is smaller in relation and one is larger. What is implied is that there is a small-circle-like-action on the large circle 
and vice versa. If the circles were the same size, there would be no smaller or larger. Thus, because a Distinction $A_{[i o]} \stackrel{\mathrm{R}}{\Longleftrightarrow} \neg A_{[i o]}$ exists, a Relationship (R) also exists where $\mathrm{R}$ is defined as the set of its action-reaction elements:

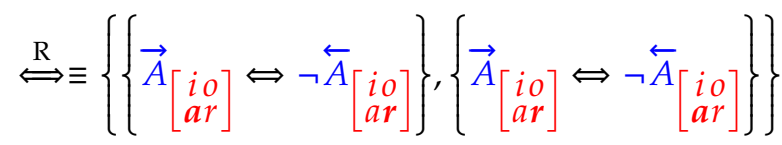

Note that in (5) any bit of information (the specific content/labels in blue) has a matrix of multiple structural variables (in red) associated with them. These are the universal patterns and elements of DSRP. For example, because $A^{\prime}$ 's reaction $(\vec{A})$ is not the same as $A$, then $\vec{A} \neq A$, which means actions and reactions are both identities (i) and others (o). In (6), unbolded red text represents structural variables that are probable and predictable but not currently manifested in use:

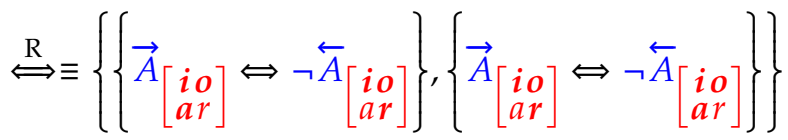

Step (3) in Table 2 illustrates that if $\geq 2$ things are related, a System $\left(S_{w}^{p}\right)$ exists, universally, where $\{i, \stackrel{R}{\Longleftrightarrow}, o\} \in w$. Importantly, DSRP Theory treats both structural parts and relational parts, as parts of the whole, because nature does. This has some rather large implications. A full discussion of emergence and the commonly held but misinformed trope that "the whole is greater than the sum of its parts" is beyond the scope of this paper (see [6] for a more complete analysis). However, it should be pointed out that the implications of accounting for (literally counting) relational elements as parts of the whole rather than de-valorizing them as many a physicist and systems scientist has done for some time, is of crucial importance. Emergence need not be any less (often) surprising, perplexing, or marvelous. However, it does resolve the pesky problem of the whole being greater than its parts, which it never is because that would defy the definition of the whole, which includes relational parts. It goes without saying that relationships must be considered parts of the whole, because they are part of the whole. The whole is always exactly equal to its parts. Represented symbolically in (7), we see that a whole $(w)$ exists with three parts (in parentheses below):

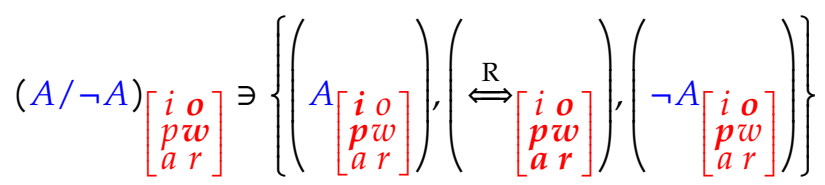

Note in Step (4) in Table 2 and also above in Equation (7) that the original system was defined entirely in terms of $A$, but could have alternatively been framed by $B$. Equation (8) shows the same system shown in Equation (7) but from a different perspective: in terms of $B$, which we originally defined in terms of $A$ as not- $A$. Thus, in Equation (7) $B$ is a function of $A$ or $(B=B(A))$, whereas in Equation (8) $A$ is a function of $B$, or $(A=A(B))$. Thus, $B=\neg A$ and $A=\neg B$. Represented symbolically in (8), we see that a whole ( $w$ ) exists with three parts (in parentheses below):

$$
\left.\left.(B / \neg B)_{\left[\begin{array}{ll}
i & o \\
p & w \\
a & r \\
\rho & v
\end{array}\right]}\right]^{\prime}\left\{\left(B\left[\begin{array}{ll}
i & o \\
p & w \\
a & r \\
\rho & v
\end{array}\right]\right), \stackrel{\mathrm{R}}{\Longleftrightarrow}\left[\begin{array}{ll}
i & o \\
p & w \\
a & r \\
\rho & v
\end{array}\right]\right),\left(\neg B\left[\begin{array}{ll}
i & o \\
p & w \\
a & r \\
\rho & v
\end{array}\right]\right)\right\}
$$




\section{Discussion}

Having walked through these logic steps, we arrive at several conclusions:

1. that if $A$ (i.e., anything) exists then DSRP structures must also exist;

2. that information variables follow the same rules and thus simultaneously act as any of the various patterns and elements of DSRP;

3. that each pattern requires all of the patterns (and therefore elements) as necessary and sufficient in order to exist, where each pattern (D, S, R, and P) consists of exchangeable $i / o$ and $\rho / v$ and each is relational and systemic.

Table 3 illustrates how each pattern itself requires the other three patterns to exist.

Table 3. DSRP are necessary and sufficient for D, S, R, and P.

\begin{tabular}{|c|c|}
\hline Self Similarity & Necessary and Sufficient \\
\hline & $\begin{array}{l}\text { Any identity-other Distinction is also: (1) Two Distinctions (pos- } \\
\text { sible): }\{i, \neg i\} \text { and }\{o, \neg o\} \text {; (2) A Relationship }\left(R_{r}^{a}\right): i \stackrel{\text { negation }}{\Longleftrightarrow} o \text {; } \\
\text { (3) A System with parts: } i, o \text {, and their relationship }\left(R_{r}^{a}\right) ;(4) \text { Two } \\
\text { Perspectives (possible): } i \text { and } o \text {. }\end{array}$ \\
\hline & $\begin{array}{l}\text { Any part-whole System is also: (1) Two Distinctions (possible): } \\
\{p, \neg p\} \text { and }\{w, \neg w\} ;(2) \text { A Relationship }\left(R_{r}^{a}\right): p \stackrel{\text { contains }}{\Longleftrightarrow} w ;(3) \text { Aelongs } \\
\text { System with parts: } p, w \text {, and their relationship }\left(R_{r}^{a}\right) ; \text { and (4) Two } \\
\text { Perspectives (possible): } p \text { and } w \text {. }\end{array}$ \\
\hline & $\begin{array}{l}\text { Any action-reaction Relationship is also: (1) Two Distinctions } \\
\text { (possible): }\{a, \neg a\} \text { and }\{r, \neg r\} ;(2) \text { A Relationship }\left(R_{r}^{a}\right): a \stackrel{\text { effect }}{\stackrel{\text { affect }}{\longrightarrow}} r \text {; } \\
\text { (3) A System with parts: } a, r \text {, and their relationship }\left(R_{r}^{a}\right) \text {; (4) Two } \\
\text { Perspectives (possible): } a \text { and } r ;(5) \text { The Relationship itself is } \\
\text { distinct (D), a whole with parts (S), and a Perspective (P). }\end{array}$ \\
\hline & $\begin{array}{l}\text { Any point-view Perspective is also: (1) Two Distinctions (possi- } \\
\text { ble): }\{\rho, \neg \rho\} \text { and }\{v, \neg v\} \text {; (2) A Relationship }\left(R_{r}^{a}\right): \rho \stackrel{\text { observed }}{\Longleftrightarrow} v \text {; } \\
\text { (3) A System with parts: } \rho, v \text {, and their relationship }\left(R_{r}^{a}\right) \text {; (4) Two } \\
\text { Perspectives (possible): } \rho \text { and } v \text {. }\end{array}$ \\
\hline
\end{tabular}

We have clarified what DSRP Theory is and what its for, but what about what DSRP Theory predicts? For that we must explore the structural predictions that result from DSRP's dynamical rules. The co-implication rule yields that D, S, R, and P are a self-similar fractal are necessary and sufficient as they co-imply each other. The simultaneity rule explains that each bit of information exists as all four patterns at once; a distinction is a system, relationship, and can be a perspective. In Figure 3, both the co-implication rule (red lines) and the simultaneity rule (blue lines) are illustrated, where each blue line could be read as "any $X$ element is predictably also a $Y$ element" or alternatively that "any bit of information has the potential (and is probable) to be structured simultaneously as both $X$ and $Y^{\prime \prime}$. The simultaneity rule can be read as "If $X$ exists, the probability that it is also a $Y$ is effectively $1.0(0.99999)$ " or alternatively " $\mathrm{X}$ is simultaneously $\mathrm{Y}^{\prime}$. This means that for each fractal ruler size (level) there are co-implications totaling $n(n-1)=8(7)=56+4=60$ possible structural predictions. The probability of simultaneity $P(s)=0.99999$ whereas the probability of co-implication $P(c)=1.0$. Each one of these (red and blue) lines represents a structural prediction that can be made at any time step, any fractal level of scale about any information bit. A structural prediction is essentially a prediction that a structure 
exists and the resulting "filling in" of information. Thus, if an entirely new virus called Newvid appeared, about which nothing is known, you might start to make some structural predictions like Newvid is $\{\longleftarrow, \longleftarrow, \ldots\}$ and Newvid is not $\{\longleftarrow, \longleftarrow, \ldots\}$; Newvid is part of $\left\{\_, \_, \ldots\right\}$ and made up of the parts $\left\{\_, \_, \ldots\right\}$; Newvid connects to $\left\{\_,-\ldots\right\}$ through $\{\longleftarrow, \longleftarrow, \ldots\}$, and, there are many different perspectives from which to look at Newvid including $\{\longleftarrow, \ldots, \ldots\}$.

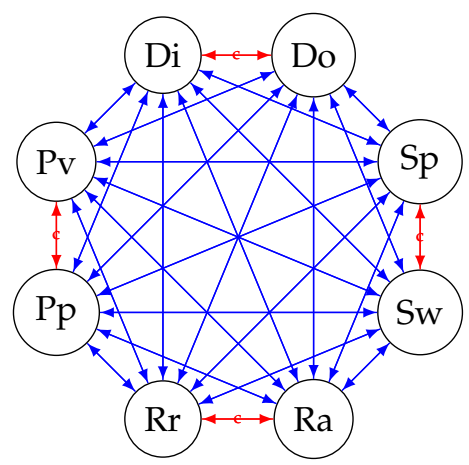

Figure 3. Visualization of the co-implication (red) and simultaneity (blue) rules of DSRP.

The co-implication rule has one postulate-if a pattern exists, its elements exist, and vice versa-with four conditions: $D \Leftrightarrow\{i \Leftrightarrow o\} ; S \Leftrightarrow\{p \Leftrightarrow w\} ; R \Leftrightarrow\{a \Leftrightarrow r\} ; P \Leftrightarrow\{\rho \Leftrightarrow v\}$. The simultaneity rule has two postulates: (1) one pattern implies all patterns. If $D$ OR $S$ OR $R$ OR $P$ exists, then $D$ AND $S$ AND $R$ AND $P$ exist. In logic notation: $\exists(D \vee S \vee R \vee P) \Longrightarrow$ $(D \wedge S \wedge R \wedge P)$. (2) One element implies all elements: If $i$ OR $o$ OR $p$ OR $w$ OR $a$ OR $r$ OR $\rho$ OR $v$ exists, then $i$ AND $o$ AND $p$ AND $w$ AND $a$ AND $r$ AND $\rho$ AND $v$ exist. In logic notation: $\exists(i \vee o \vee p \vee w \vee a \vee r \vee \rho \vee v) \Longrightarrow(i \wedge o \wedge p \wedge w \wedge a \wedge r \wedge \rho \wedge v)$.

What does this all look like in applied terms? Imagine the complexity of this network if it took into account the DSRP rules where:

- $\quad$ every edge is a (relational) node. [Pay attention, this one rule alone leads to networks that are rarely explicated but universal in nature.];

- $\quad$ every node is a sub-network;

- $\quad$ every node is co-defined by all the other nodes;

- $\quad$ every node has a point of view (which effects its behavior).

We can see a simplified example of this in Figure 4 where we can predict that every node is defined by every other node in that node's context. We can predict that nodes will be (and will not be) related and we can predict that where they are related, each edge is a material node (D) with material parts (S), making it a whole. That every node (including edge nodes) can be a distinct, boundaried system made up of parts and perspective as indicated by 80 . Additionally, we can predict that every node has a unique perspective (indicated by blue nodes) on its locality. Even meta-systems such as those shown in light red and blue exist across the larger system and even those systems can be related by distinguished and systematized nodes.

Indeed, DSRP Theory is not saying that this could be the case for all networks, but that it is highly probable that it is the case, always. For example, in one of the most complex networks - the Internet-each node (i.e., a domain or individual html page) is actually a unique identity and a whole made up of parts. Each relational edge is actually a distinct thing (a hyperlink) which itself is actually a whole made up of parts (i.e., an A-ref html opening tag, url, link title, anchor text, and A-ref closing tag). Each webpage is a perspective on the Internet itself (on what it connects to and does not, what it recognizes and does not, and where it sits in a hierarchical structure, not to mention it has its own page-level statistics, etc.) Further, structural predictions help us navigate these probable real structures to decide which to acknowledge or ignore. 


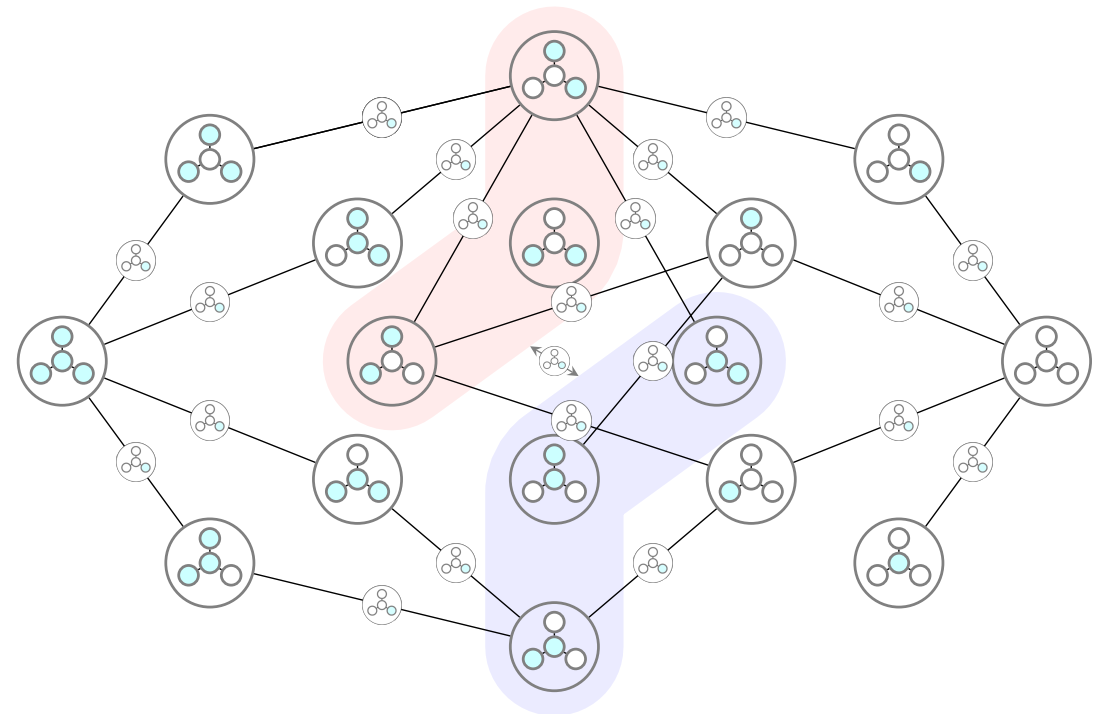

Figure 4. The predictable structural complexity of a DSRP network $\gg$ traditional network theory.

This means that in order for any identity to exist, all four structures of DSRP, each with two elements (identity-other, part-whole, action-reaction, and point-view), are necessary and sufficient $[14,15]$. In other words, for any thing to exist-either in mind or in nature-all of DSRP is necessary and sufficient. The same DSRP structure described at the microscale for a single thing to exist, carries out fractally across scale into larger and larger complexes of things both in mind and in nature. Incidentally, long before anyone spoke of the phenomena of DSRP, your mind and nature had already been doing it for a very long time... In order to go from thinking (cognition) to systems thinking (cognitive complexity) metacognition (awareness of one's thinking and mental models) is necessary. Making DSRP rules explicit, increases metacognition and allows one to make structural predictions that lead to new knowledge, innovation, invention, insights, and discovery. The DSRP simple rules can be taught (and have successfully been) to preschoolers or newcomers in a few minutes. They can get started by asking four simple questions:

1. What things are we seeing/not seeing?

2. How are these things grouped?

3. How are these things related?

4. From what or whose perspective?

Structural predictions take a very simple stepwise form that is manageable and useful, shown in Table 4. Note that there are many more structural predictions that can be converted into basic questions than the examples provided (e.g., Is (fish) a part (of a larger whole)? Or, does (fish) have a point (of view)?) For a more complete set of questions and examples see cabreraresearch.org/thinkquiry, (accessed on 1 December 2021) and [4,165].

One can quickly see that, once information is combined with structural organization, there are too many structural predictions possible to account for herein. This is especially true when one considers that structural predictions can be made for doubles, triples, quadruples, and n-tuples. However, if we simply take the case of doubles at the pattern and element level, the results are manageable and incredibly useful as shown in Tables 5 and 6.

DSRP is a fractal - which means it exists at and can be purposefully applied to fractured dimensions of scale. The idea of "fractured" dimensions can be traced back to the 1600s and was explored by Benoit Mandelbrot in 1967 [166] who cited Lewis Fry Richardson's previous research. Mandelbrot coined the terms "fractional dimensions" or "fractal" in 1975. The basic idea, shown in Figure 5, is that the smaller the ruler the longer the coastline, or more generally speaking, a change in scale results in a subsequent change in detail. 
Table 4. The steps to structural predictions.

\begin{tabular}{ll}
\hline Step & Word Form \\
\hline Step 1: Start with some thing (any thing). & What is the identity? (fish) \\
$\begin{array}{l}\text { Step 2: Predict a structural container and } \\
\text { label it with a question mark (?). }\end{array}$ & $\begin{array}{l}\text { Is (fish) a whole (made up of } \\
\text { parts)? Is (fish) related to } \\
\text { something? }\end{array}$ \\
$\begin{array}{l}\text { Step 3: Fill "empty structure" with } \\
\text { information you discover (through } \\
\text { search, research, observation, etc.) to } \\
\begin{array}{l}\text { discover new knowledge (about your } \\
\text { topic) based on the universal structure of } \\
\text { knowledge and nature. }\end{array}\end{array}$ & $\begin{array}{l}\text { A fish has parts: fins and gills. } \\
\text { Fins are related to plankton. }\end{array}$ \\
\hline
\end{tabular}

Table 5. Structural predictions of 2-pattern combinations at pattern level.

\begin{tabular}{|c|c|c|c|c|}
\hline Patterns & D & $S$ & $\mathbf{R}$ & $\mathbf{P}$ \\
\hline D & & $\begin{array}{c}\text { An } \mathbf{S} \text { is predictably } \\
\text { a D }\end{array}$ & $\begin{array}{c}\text { An } \mathbf{R} \text { is predictably } \\
\text { a } \mathbf{D}\end{array}$ & $\begin{array}{c}\text { A } \mathbf{P} \text { is predictably a } \\
\text { D }\end{array}$ \\
\hline $\mathrm{S}$ & $\begin{array}{c}\text { A D is predictably an } \\
\mathbf{S}\end{array}$ & & $\begin{array}{c}\text { An } \mathbf{R} \text { is predictably } \\
\text { an } \mathbf{S}\end{array}$ & $\begin{array}{c}\text { A } \mathbf{P} \text { is predictably } \\
\text { an } \mathbf{S}\end{array}$ \\
\hline $\mathbf{R}$ & A D is predictably an & $\begin{array}{c}\text { An } \mathbf{S} \text { is predictably } \\
\text { an } \mathbf{R}\end{array}$ & & $\begin{array}{c}\text { A } \mathbf{P} \text { is predictably } \\
\text { an } \mathbf{R}\end{array}$ \\
\hline $\mathbf{P}$ & A $\mathbf{D}$ is predictably a $\mathbf{P}$ & $\begin{array}{c}\text { An } \mathbf{S} \text { is predictably } \\
\text { a } \mathbf{P}\end{array}$ & $\begin{array}{c}\text { An } \mathbf{R} \text { is predictably } \\
\text { a } \mathbf{P}\end{array}$ & \\
\hline
\end{tabular}

Table 6. Structural predictions of 2-element combinations at element level.

\begin{tabular}{|c|c|c|c|c|c|c|c|c|}
\hline Elements & Identity & Other & Part & Whole & Action & Reaction & Point & View \\
\hline identity & & $\begin{array}{l}\text { An other is } \\
\text { predictably } \\
\text { an identity }\end{array}$ & $\begin{array}{l}\text { A part is } \\
\text { predictably } \\
\text { an identity }\end{array}$ & $\begin{array}{l}\text { A whole is } \\
\text { predictably } \\
\text { an identity }\end{array}$ & $\begin{array}{l}\text { An action is } \\
\text { predictably } \\
\text { an identity }\end{array}$ & $\begin{array}{l}\text { A reaction is } \\
\text { predictably } \\
\text { an identity }\end{array}$ & $\begin{array}{l}\text { A point is } \\
\text { predictably } \\
\text { an identity }\end{array}$ & $\begin{array}{l}\text { A view is } \\
\text { predictably } \\
\text { an identity }\end{array}$ \\
\hline other & $\begin{array}{c}\text { An identity } \\
\text { is } \\
\text { predictably } \\
\text { an other }\end{array}$ & & $\begin{array}{l}\text { A part is } \\
\text { predictably } \\
\text { an other }\end{array}$ & $\begin{array}{l}\text { A whole is } \\
\text { predictably } \\
\text { an other }\end{array}$ & $\begin{array}{l}\text { An action is } \\
\text { predictably } \\
\text { an other }\end{array}$ & $\begin{array}{l}\text { A reaction is } \\
\text { predictably } \\
\text { an other }\end{array}$ & $\begin{array}{l}\text { A point is } \\
\text { predictably } \\
\text { an other }\end{array}$ & $\begin{array}{l}\text { A view is } \\
\text { predictably } \\
\text { an other }\end{array}$ \\
\hline part & $\begin{array}{c}\text { An identity } \\
\text { is } \\
\text { predictably } \\
\text { a part }\end{array}$ & $\begin{array}{c}\text { An other is } \\
\text { predictably } \\
\text { a part }\end{array}$ & & $\begin{array}{c}\text { A whole is } \\
\text { predictably } \\
\text { a part }\end{array}$ & $\begin{array}{c}\text { An action is } \\
\text { predictably } \\
\text { a part }\end{array}$ & $\begin{array}{c}\text { A reaction is } \\
\text { predictably } \\
\text { a part }\end{array}$ & $\begin{array}{c}\text { A point is } \\
\text { predictably } \\
\text { a part }\end{array}$ & $\begin{array}{c}\text { A view is } \\
\text { predictably } \\
\text { a part }\end{array}$ \\
\hline whole & $\begin{array}{c}\text { An identity } \\
\text { is } \\
\text { predictably } \\
\text { a whole }\end{array}$ & $\begin{array}{l}\text { An other is } \\
\text { predictably } \\
\text { a whole }\end{array}$ & $\begin{array}{c}\text { A part is } \\
\text { predictably } \\
\text { a whole }\end{array}$ & & $\begin{array}{l}\text { An action is } \\
\text { predictably } \\
\text { a whole }\end{array}$ & $\begin{array}{l}\text { A reaction is } \\
\text { predictably } \\
\text { a whole }\end{array}$ & $\begin{array}{l}\text { A point is } \\
\text { predictably } \\
\text { a whole }\end{array}$ & $\begin{array}{c}\text { A view is } \\
\text { predictably } \\
\text { a whole }\end{array}$ \\
\hline action & $\begin{array}{c}\text { An identity } \\
\text { is } \\
\text { predictably } \\
\text { an action }\end{array}$ & $\begin{array}{l}\text { An other is } \\
\text { predictably } \\
\text { an action }\end{array}$ & $\begin{array}{l}\text { A part is } \\
\text { predictably } \\
\text { an action }\end{array}$ & $\begin{array}{l}\text { A whole is } \\
\text { predictably } \\
\text { an action }\end{array}$ & & $\begin{array}{l}\text { A reaction is } \\
\text { predictably } \\
\text { an action }\end{array}$ & $\begin{array}{l}\text { A point is } \\
\text { predictably } \\
\text { an action }\end{array}$ & $\begin{array}{l}\text { A view is } \\
\text { predictably } \\
\text { an action }\end{array}$ \\
\hline reaction & $\begin{array}{l}\text { An identity } \\
\text { is } \\
\text { predictably } \\
\text { a reaction }\end{array}$ & $\begin{array}{l}\text { An other is } \\
\text { predictably } \\
\text { a reaction }\end{array}$ & $\begin{array}{l}\text { A part is } \\
\text { predictably } \\
\text { a reaction }\end{array}$ & $\begin{array}{l}\text { A whole is } \\
\text { predictably } \\
\text { a reaction }\end{array}$ & $\begin{array}{l}\text { An action is } \\
\text { predictably } \\
\text { a reaction }\end{array}$ & & $\begin{array}{l}\text { A point is } \\
\text { predictably } \\
\text { a reaction }\end{array}$ & $\begin{array}{l}\text { A view is } \\
\text { predictably } \\
\text { a reaction }\end{array}$ \\
\hline point & $\begin{array}{c}\text { An identity } \\
\text { is } \\
\text { predictably } \\
\text { a point }\end{array}$ & $\begin{array}{l}\text { An other is } \\
\text { predictably } \\
\text { a point }\end{array}$ & $\begin{array}{l}\text { A part is } \\
\text { predictably } \\
\text { a point }\end{array}$ & $\begin{array}{l}\text { A whole is } \\
\text { predictably } \\
\text { a point }\end{array}$ & $\begin{array}{l}\text { An action is } \\
\text { predictably } \\
\text { a point }\end{array}$ & $\begin{array}{c}\text { A reaction is } \\
\text { predictably } \\
\text { a point }\end{array}$ & & $\begin{array}{c}\text { A view is } \\
\text { predictably } \\
\text { a point }\end{array}$ \\
\hline view & $\begin{array}{c}\text { An identity } \\
\text { is } \\
\text { predictably } \\
\text { a view }\end{array}$ & $\begin{array}{c}\text { An other is } \\
\text { predictably } \\
\text { a view }\end{array}$ & $\begin{array}{c}\text { A part is } \\
\text { predictably } \\
\text { a view }\end{array}$ & $\begin{array}{c}\text { A whole is } \\
\text { predictably } \\
\text { a view }\end{array}$ & $\begin{array}{c}\text { An action is } \\
\text { predictably } \\
\text { a view }\end{array}$ & $\begin{array}{c}\text { A reaction is } \\
\text { predictably } \\
\text { a view }\end{array}$ & $\begin{array}{l}\text { A point is } \\
\text { predictably } \\
\text { a view }\end{array}$ & \\
\hline
\end{tabular}



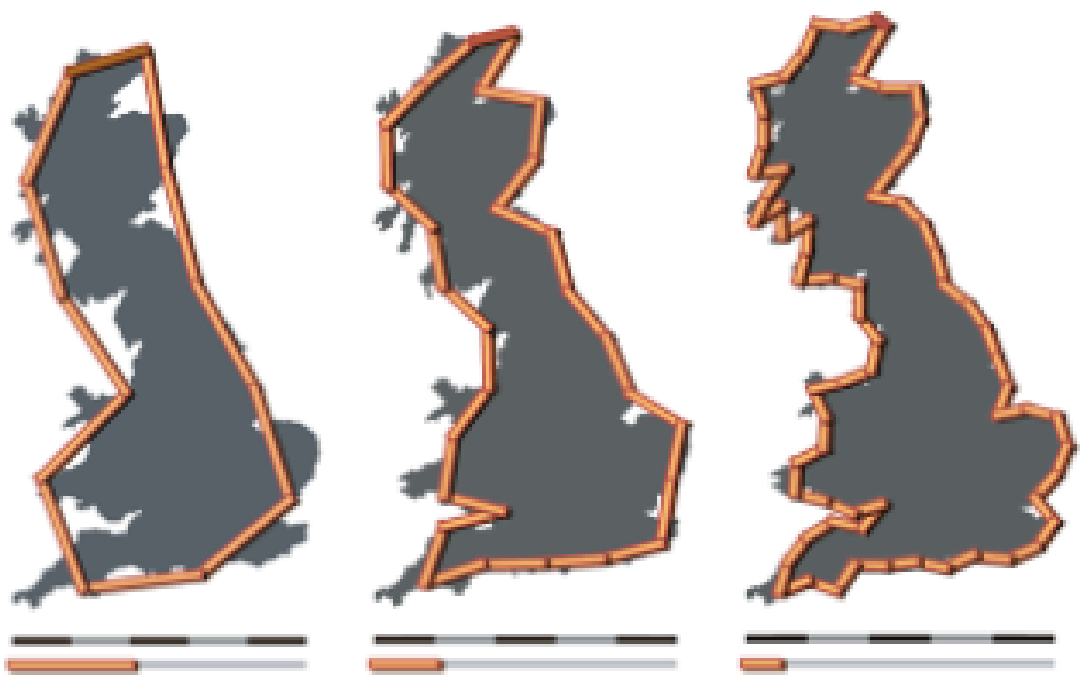

Figure 5. Fractals and ruler size

DSRP is a fractal and therefore the operations (rules) can be carried out at different levels of scale, on different dimensions, or based on different sizes of "rulers". For example, the DSRP rules (both structural (patterns and elements) and dynamical (co-implication and simultaneity)) can be applied at the microlevel, affecting only DSRP structures. The rules can be applied at the neurological level (the level of synapses and neurons), or at the psychological level (feelings and thinkings, beliefs, mindsets, and biases) as well as the sociological level (the level where we socially mitigate and negotiate shared mental models, memes, belief systems, culture, etc.). These are just different-sized rulers for the same coastline. To understand fractal dimensionality one must distinguish it from "normal" dimensionality (a.k.a., Euclidian) and also "topical dimensionality" (a.k.a., Lebesgue) which although different are roughly similar in that an entity (point, line, plane, polyhedra, and time) are respectively compared with their dimensionality (respectively, 0,1,2,3,4). The Koch snowflake is a good example. Topologically it is one dimensional because it is a "line" yet the length between any two of its points is infinite. Therefore, no part of the Koch snowflake-no matter how small-is "line-like" because it is made up of an infinite number of angled segments. Thus, its fractional dimensionality can be thought of as too simple to be 2-dimensional but too complex to be 1 dimensional. Its fractal dimension exists in between these two dimensions at $\approx 1.262$. The fractal dimension, in this case, can range from 1.0 to 2.0. A low fractal dimension (1.1 or 1.2) may behave very much like a line. However, a larger fractal dimension (1.9) has interesting properties in that as it fills the space of an area it acts as if it is filling the space of a volume. This means that when we scale volume we get significantly greater growth than when we scale area. Carried out in 2 topical dimensions (a plane) the Koch snowflake looks and grows fractally according to its dimensions. It exhibits self-similarity where any part is exactly similar to the whole and where it is difficult to know at what level of scale one is at. The fractal dimension, in this case, can range from 1.0 to 2.0. A low fractal dimension (1.1 or 1.2) may behave very much like a line. However, a larger fractal dimension (1.9) has interesting properties in that as it fills the space of an area it acts as if it is filling the space of a volume. The area increases with the square of the lengths (which holds true for any two-dimensional shapes). For example, if we compare the following lengths to their areas ( $1 \mathrm{ft}: 1 \times 1=1 \mathrm{sq}$. ft.; $2 \mathrm{ft}: 2 \times 2=4 \mathrm{sq}$. $\mathrm{ft}$.; $3 \mathrm{ft}$ : $3 \times 3=9$ sq. ft.; $4 \mathrm{ft}: 4 \times 4=16$ sq. ft.; $5 \mathrm{ft}: 5 \times 5=25$ sq. ft.; $\mathrm{nft}: \mathrm{n} \times \mathrm{n}=n^{2}$ sq. ft.). The same is true for volumes. If we scale a factor of 2 (say $1 \mathrm{ft}$ to $2 \mathrm{ft}$ ) the volume of 1 cubic foot will increase to 8 cubic feet. The volume will increase with the cube of its linear dimensions (factor of 2: volume of $2 \times 2 \times 2=8 \mathrm{cu}$. ft.; factor of 3: volume of $3 \times 3 \times 3=27 \mathrm{cu}$. ft.; factor of 4: volume of $4 \times 4 \times 4=64 \mathrm{cu}$. ft.; factor of $\mathrm{n}$ : volume of $\mathrm{n} \times \mathrm{n} \times \mathrm{n}=\mathrm{n}^{3} \mathrm{cu}$. ft.). This means that when we scale volume we get significantly greater growth than when we 
scale area. Now let us return to fractals or fractal dimensions. When fractal dimensions are higher $(1.8,1.9)$ the scaling effects act more like volume scaling than like area scaling. This means that we get more "space filling" due to the fractal structure. This additional dimension means that fractals fill and scale more like 3-dimensional volumes than they do 2-dimensional areas. Geoffrey West [167] explains it this way,

"A crinkly enough line that is space filling can scale as if it's an area. Its fractality effectively endows it with an additional dimension. Its conventional Euclidian dimension... still has the value 1 , indicating that it's a line, but its fractal dimension is 2, indicating that it's maximally fractal and scaling as if it were an area. In similar fashion an area, if crinkly enough, can behave as if it's a volume, thereby gaining an effective extra dimension: its Euclidian dimension is 2, indicating it's an area, but it's fractal dimension is $3^{\prime \prime}$.

DSRP is a fractal, self-similar repeating structure. It applies a simple ruleset across scales from the tiniest to the largest phenomena. If one thinks of an identity as a simple line segment, D, S, R, and P provide additional rules of transformation to that line segment, similar to the Koch snowflake, thus space filling as if it was an area. This is illustrated in the idea that four also comes from the fractal space filling and scaling laws. Where does the "magical" number four come from? West [167] explains,

This additional dimension... leads to organisms' functioning as if they are operating in four dimensions. This is the geometric origin of the quarter-power law. Thus, instead of scaling with classic $1 / 3$ exponents, as would be the case if they were smooth nonfractal Euclidian objects, they scale with $1 / 4$ exponents. Although living things occupy a three-dimensional space, their internal physiology and anatomy operate as if they were four-dimensional. (p. 153)

This, perhaps more than any other explanation, explains why there are four patterns and not 5 , or 9.2 , or 37 , etc.). In nature, the number four appears with spooky regularity.

Indeed, as a subset of shared cognition at the sociological level, science represents a truly systemic enterprise. No thinking is more systemic than scientific thinking in the aggregate. This is because science is a collective cognition that continually tests against reality over time in a transparent way (and includes many people, all critiquing and adapting the work of others). In other words, the scientific thinking of a single scientist may not be systemic (indeed, it may be quite the opposite). However, scientific thinking, over time and in the aggregate, becomes increasingly systemic because different people see things from different perspectives. This does not mean that every thought of every scientist is "systemic". It means that as a collective action, over time, the emergent property (governed by DSRP) is that science becomes systemic. For a representation of DSRP as a fractal, see Figure 6, where it is akin to (at top) 2D Cantor dust $\left(\log _{3}(4)\right)$ for four patterns and/or (at bottom) 3D Cantor dust $\left(\log _{3}(8)\right)$ for eight elements. This also illustrates why the 4 DSRP patterns can be used effectively without the elements, but also why the eight elements provide a "dimensional" level of sophistication in more specialized or technical applications.

In DSRP, as in any fractal, the size of your ruler matters. Figure 1 illustrates the ST/DSRP Loop in action at the basic human scale $\left(\approx 10^{0} \mathrm{~m}\right)$. The central idea of DSRP Theory is the idea that there are universals of organization both in mind and in nature-an idea supported by empirical evidence. Because DSRP is a fractal, structural predictions can be made at any level of scale across micro and macro states in individual and collective cognition. The analytical specificity provided by DSRP Theory, combined with its integral dynamics offers a level of detail that makes analysis and synthesis possible and makes it possible to measure systems thinking. 

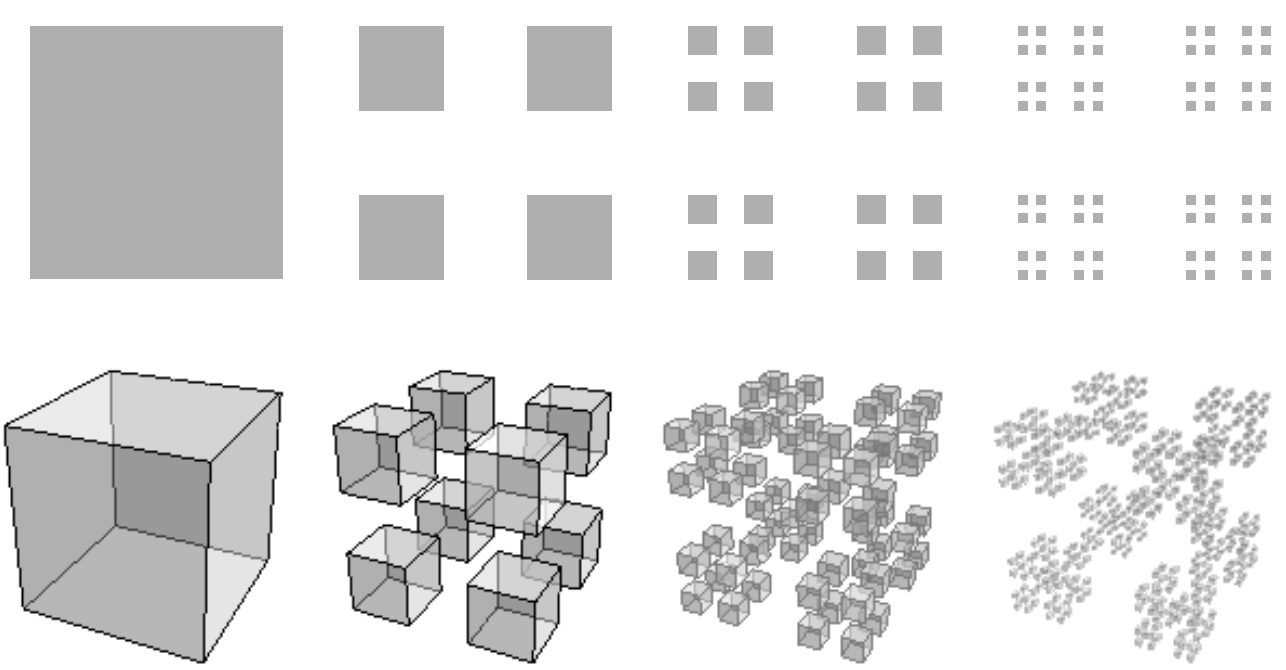

Figure 6. DSRP's fractal dimensionality.

\title{
5. Conclusions
}

The implications of DSRP Theory are many-fold but in many ways this is for history to judge. Systems thinking and systems science historians, however, such as Gerald Midgley have strongly suggested that DSRP Theory may have already launched a fourth wave in the field which fundamentally alters the practitioner paradigm as well as the research program of the field moving forward.

Author Contributions: Authors contributed equally in methodology, software, validation, formal analysis, investigation, resources, data curation, writing —original draft preparation, writing-review and editing, visualization, supervision, project administration, and funding acquisition. Development of DSRP Theory, D.C. All authors have read and agreed to the published version of the manuscript.

Funding: This research received no external funding.

Institutional Review Board Statement: Ethical review and approval were waived for this study, due to no collection of personal or identifying data.

Data Availability Statement: The data presented in this study are available on request from the corresponding author. The data are not publicly available due to privacy, human subjects, and ethical considerations.

Conflicts of Interest: The authors declare no conflict of interest.

\author{
Abbreviations \\ The following abbreviations are used in this manuscript: \\ DSRP DSRP Theory (Distinctions, Systems, Relationships, Perspectives) \\ D identity-other Distinctions \\ S part-whole Systems \\ $\mathrm{R} \quad$ action-reaction Relationships \\ P point-view Perspectives \\ ST Systems Thinking \\ STMI Systems Thinking and Metacognition Inventory \\ RDS Relate-Distinguish-Systematize Jig
}

\section{References}

1. Cabrera, D.; Cabrera, L.; Lobdell, C. Systems Thinking. J. Eval. Program Plan. 2008, 31, 299-310. [CrossRef] [PubMed]

2. Cabrera, D.; Cabrera, L. Complexity and Systems Thinking Models in Education: Applications for Leaders. In Learning, Design, and Technology: An International Compendium of Theory, Research, Practice, and Policy; Spector, M.J., Lockee, B.B., Childress, M.D., Eds.; Springer International Publishing: Cham, Switzerland, 2019; pp. 1-29. 
3. Cabrera, D.; Cabrera, L. What Is Systems Thinking? In Learning, Design, and Technology: An International Compendium of Theory, Research, Practice, and Policy; Spector, M.J., Lockee, B.B., Childress, M.D., Eds.; Springer International Publishing: Cham, Switzerland, 2019; pp. 1-28.

4. Cabrera, L.; Cabrera, D. The Simple Rules of Complex Networks: Heuristics for Structural Predictions. In The Routledge Handbook for Systems Thinking; Cabrera, L., Cabrera, D., Midgley, G., Eds.; Routledge Press: London, UK, 2022.

5. Cabrera, D.; Cabrera, L. Distinctions, Systems, Relationships, and Perspectives (DSRP): A Theory of Thinking and of Things. J. Eval. Program Plan. 2008, 31, 311-317. [CrossRef] [PubMed]

6. Cabrera, D. Systems Thinking; Cornell University: Ithaca, NY, USA, 2006.

7. Cabrera, D.; Cabrera, L.; Midgley, G. (Eds.) The Four Waves of Systems Thinking. In The Routledge Handbook for Systems Thinking; Routledge Press: London, UK, 2021.

8. Cabrera, D. Scientific Journal of Derek Cabrera. 1997. Available online: https://tinyurl.com/d2kut8hw (accessed on 1 December 2021).

9. Cabrera, D.A. Knowledge Age Operating System: Four Principles of Organizational Design; Project N Press: Loveland, CO, USA, 2000.

10. Cabrera, D.; Cabrera, L.; Cabrera, E. Perspectives Organize Information in Mind and Nature: Empirical Findings of Point-View Perspective $(\mathrm{P})$ in Cognitive and Material Complexity. Systems 2022, under process.

11. Cabrera, D.; Cabrera, L.; Cabrera, E. Distinctions Organize Information in Mind and Nature: Empirical Findings of Identity-Other Distinctions (D) in Cognitive and Material Complexity. Systems 2022, under process.

12. Cabrera, D.; Cabrera, L.; Cabrera, E. Relationships Organize Information in Mind and Nature: Empirical Findings of ActionReaction Relationships (R) in Cognitive and Material Complexity. Systems 2022, under process.

13. Cabrera, D.; Cabrera, L.; Cabrera, E. Systems Organize Information in Mind and Nature: Empirical Findings of Part-Whole Systems (S) in Cognitive and Material Complexity. Systems 2022, under process.

14. Cabrera, D.; Cabrera, L.; Cabrera, E.; Hernandez, O.; Sukhbaatar, U.; Kand Benitez Collante, A.E.; Lemaiyan, E.; Warugongo, N.; Sekyere, A.; Silas, D.; et al. The Origin of Ideas: Empirical Studies in Cognitive Complexity; Odyssean Press: Ithaca, NY, USA, 2022.

15. Cabrera, D.; Cabrera, L.; Midgley, G. (Eds.) Routledge Handbook of Systems Thinking; Routledge: London, UK, 2022.

16. Cabrera, D.; Cabrera, L.; Cabrera, E. A Literature Review of the Universal Patterns and Atomic Elements of Complex Cognition. In Routledge Handbook of Systems Thinking; Cabrera, D., Cabrera, L., Midgley, G., Eds.; Routledge: Ithaca, NY, USA, 2022.

17. Cabrera, L.; Sokolow, J.; Cabrera, D. Developing and Validating a Measurement of Systems Thinking: The Systems Thinking and Metacognitive Inventory (STMI). In The Routledge Handbook for Systems Thinking; Cabrera, L., Cabrera, D., Midgley, G., Eds.; Routledge Press: London, UK, 2022.

18. Midgley, G. Systems Thinking. Volume 1: General Systems Theory, Cybernetics and Complexity; Sage Publications Ltd.: London, UK, 2002.

19. François, C. International Encyclopedia of Systems and Cybernetics; Walter de Gruyter: Berlin, Germany, 2011.

20. Schwarz, E.; Durant, W. Some Streams of Systemic Thought; International Institute for General Systems Studies: Slippery Rock, PA, USA, 2001

21. Jackson, M.C.; Keyes, F. Towards a System of Systems Methodologies. J. Oper. Res. Soc. 1984, 35, 473-486. [CrossRef]

22. Jackson, M.C. Critical Systems Thinking and the Management of Complexity, 1st ed.; Wiley: Hoboken, NJ, USA, 2019.

23. Spencer-Brown, G. Laws of Form; Allen \& Unwin: London, UK, 1969.

24. Krauss, L. Why Is There Something Instead of Nothing? Simon and Schuster: New York, NY, USA, 2012.

25. Euler, L. Solutio problematis ad geometriam situs pertinentis. Comment. Acad. Sci. Petrop. 1735, 8, 128-140.

26. Kolata, G. Studying Learning in the Womb. Science 1984, 225, 302-303. [CrossRef] [PubMed]

27. Partanen, E.; Kujala, T.; Näätänen, R.; Liitola, A.; Sambeth, A.; Huotilainen, M. Learning-induced neural plasticity of speech processing before birth. Proc. Natl. Acad. Sci. USA 2013, 110, 15145-15150. [CrossRef]

28. Quinn, P.C.; Brown, C.R.; Streppa, M.L. Perceptual Organization of Complex Visual Configurations by Young Infants. Infant Behav. Dev. 1997, 20, 35-46. [CrossRef]

29. Newman, R.S.; Jusczyk, P.W. The Cocktail Party Effect in Infants. Percept Psychophys 1996, 58, 1145-1156. [CrossRef]

30. Gauthier, I.; Tarr, M.J. Becoming a "Greeble" expert: Exploring mechanisms for face recognition. Vis. Res. 1997, 37, 1673-1682. [CrossRef]

31. Aubin, T.; Jouventin, P. Cocktail-party effect in king penguin colonies. Proc. R. Soc. Lond. Ser. B-Biol. Sci. 1998, $265,1665-1673$. [CrossRef]

32. Fry, S.N.; Wehner, R. Honey bees store landmarks in an egocentric frame of reference. J. Comp. Physiol. A-Neuroethol. Sens. Neural Behav. Physiol. 2002, 187, 1009-1016. [CrossRef] [PubMed]

33. Badre, D. Cognitive control, hierarchy, and the rostro-caudal organization of the frontal lobes. Trends Cogn. Sci. 2008, 12, 193-200. [CrossRef] [PubMed]

34. Bukach, C.M.; Gauthier, I.; Tarr, M.J.; Kadlec, H.; Barth, S.; Ryan, E.; Turpin, J.; Bub, D.N. Does acquisition of Greeble expertise in prosopagnosia rule out a domain-general deficit? Neuropsychologia 2012, 50, 289-304. [CrossRef]

35. Drews, G. Contributions of Theodor Wilhelm Engelmann on Phototaxis, Chemotaxis, and Photosynthesis. Photosynth. Res. 2005, 83, 25-34. [CrossRef] [PubMed]

36. Sengupta, A.; Kruppa, T.; Löwen, H. Chemotactic Predator-Prey Dynamics. arXiv 2010, arXiv:1009.5521. 
37. Berleman, J.E.; Kirby, J.R. Deciphering the hunting Strategy of a Bacterial Wolfpack. FEMS Microbiol. Rev. 2009, 33, 942-957. [CrossRef] [PubMed]

38. Pradel, E.; Zhang, Y.; Pujol, N.; Matsuyama, T.; Bargmann, C.I.; Ewbank, J.J. Detection and Avoidance of a Natural Product from the Pathogenic Bacterium Serratia Marcescens by Caenorhabditis Elegans. Proc. Natl. Acad. Sci. USA 2007, 104, 2295-2300. [CrossRef]

39. Rajalingham, R.; DiCarlo, J.J. Reversible Inactivation of Different Millimeter-Scale Regions of Primate IT Results in Different Patterns of Core Object Recognition Deficits. Neuron 2019, 102, 493-505. [CrossRef]

40. Clark, T. National Boundaries, Border Zones, and Marketing Strategy: A Conceptual Framework and Theoretical Model of Secondary Boundary Effects. J. Mark. 1994, 58, 67-80. [CrossRef]

41. Coye, D. The Sneakers/Tennis Shoes Boundary. Am. Speech 1986, 61, 366-369. [CrossRef]

42. Powers, E.; Cabrera, L.; Cabrera, D. No Word Is an Island: Distinguishing "Nerd" and "Geek". In Cognitive Case Study; Cornell University Press: Ithaca, NY, USA, 2016.

43. Cabrera, D.; Cabrera, L. Systems Thinking Made Simple: New Hope for Solving Wicked Problems in a Complex World; Odyssean Press: Ithaca, NY, USA, 2015.

44. Peterson, M.A.; Skow-Grant, E. Memory and Learning in Figure-Ground Perception; Psychology of Learning and Motivation; Academic Press: Cambridge, MA, USA, 2003; pp. 1-35. [CrossRef]

45. Abdullah, M.H.; Klypin, A.; Wilson, G. Cosmological Constraints on $\Omega \mathrm{m}$ and $\sigma 8$ from Cluster Abundances Using the GalWCat19 Optical-spectroscopic SDSS Catalog. ApJ 2020, 901, 90. [CrossRef]

46. De Luca Picione, R.; Valsiner, J. Psychological Functions of Semiotic Borders in Sense-Making: Liminality of Narrative Processes Eur. J. Psychol. Assess. 2017, 13, 532-547. [CrossRef] [PubMed]

47. Glanville, R. The Self and the Other: The Purpose of Distinction. In "Cybernetics and Systems '90" the Proceedings of the European Meeting on Cybernetics and Systems Research; Trappl, R., Ed.; World Scientific: Singapore, 1999.

48. Durand, R.; Calori, R. Sameness, Otherness? Enriching Organizational Change Theories with Philosophical Considerations on the Same and the Other. AMRO 2006, 31, 93-114. [CrossRef]

49. Gillette, J.M. Boundary Lines of Social Phenomena. Am. J. Sociol. 1925, 30, 585-593. [CrossRef]

50. Tajfel, H.; Wilkes, A.L. Classification and quantitative judgement. Br. J. Psychol. 1963, 54, 101-114. [CrossRef]

51. Davies, C. Sexual Taboos and Social Boundaries. Am. J. Sociol. 1982, 87, 1032-1063. [CrossRef]

52. Langer, E.J.; Bashner, R.S.; Chanowitz, B. Decreasing Prejudice by Increasing Discrimination. J. Personal. Soc. Psychol. 1985, 49, 113-120. [CrossRef]

53. Perdue, C.W.; Dovidio, J.F.; Gurtman, M.B.; Tyler, R.B. Us and Them: Social Categorization and the Process of Intergroup Bias. J. Personal. Soc. Psychol. 1990, 59, 475-486. [CrossRef]

54. Leudar, I.; Marsland, V. On membership categorization: 'us', 'them' and 'doing violence' in political discourse. Discourse Soc. 2004, 15, 243-266. [CrossRef]

55. Young, J. On Insiders (Emic) and Outsiders (Etic): Views of Self, and Othering. Syst. Pract. Action Res. 2005, 18, 151-162. [CrossRef]

56. Midgley, G.; Pinzón, L.A. Systemic mediation: Moral reasoning and boundaries of concern: Systemic mediation. Syst. Res. Behav. Sci. 2013, 30, 607-632. [CrossRef]

57. Bentley, S.V.; Greenaway, K.H.; Haslam, S.A. Cognition in context: Social inclusion attenuates the psychological boundary between self and other. J. Exp. Soc. Psychol. 2017, 73, 42-49. [CrossRef]

58. King, S.L.; Connor, R.C.; Krützen, M.; Allen, S.J. Cooperation-based concept formation in male bottlenose dolphins. Nat. Commun. 2021, 12, 2373. [CrossRef] [PubMed]

59. Stafstrom, J.A.; Menda, G.; Nitzany, E.I.; Hebets, E.A.; Hoy, R.R. Ogre-Faced, Net-Casting Spiders Use Auditory Cues to Detect Airborne Prey. Curr. Biol. 2020, 30, 5033-5039.e3. [CrossRef] [PubMed]

60. Rubin, N. Figure and ground in the brain. Nat. Neurosci. 2001, 4, 857-858. [CrossRef]

61. Baylis, G.C.; Driver, J. Shape-coding in IT cells generalizes over contrast and mirror reversal, but not figure-ground reversal. Nat. Neurosci. 2001, 4, 937-942. [CrossRef]

62. Bateson, G. Form Substance and Difference; Etc. 2015; Volume 72, pp. 90-104. Available online: http://www.jstor.org/stable/24 761998 (accessed on 1 December 2021).

63. Darwin, C. On the Origin of Species: By Means of Natural Selection, or the Preservation of Favoured Races in the Struggle for Life; John Murray: London, UK, 1859.

64. Bertalanffy. The History and Status of General Systems Theory. Acad. Manag. J. 1972, 15, 407-426. [CrossRef]

65. Rittel, H.W.J.; Webber, M.M. Dilemmas in a General Theory of Planning. Policy Sci. 1973, 4, 155-169. [CrossRef]

66. Marchal, J.H. On the Concept of a System. Philos. Sci. 1975, 42, 448-468. [CrossRef]

67. Goguen, J.A.; Varela, F.J. Systems And Distinctions: Duality And Complementarity. Int. J. Gen. Syst. 1979, 5, 31-43. [CrossRef]

68. Ivan, M.; Kondo, K.; Yang, H.; Kim, W.; Valiando, J.; Ohh, M.; Salic, A.; Asara, J.M.; Lane, W.S.; Kaelin, W.G., Jr. HIFa Targeted for VHL-Mediated Destruction by Proline Hydroxylation: Implications for O Sensing. Science 2001, 292, 464-468. [CrossRef] [PubMed]

69. Chen, P.; Fan, D.; Zhang, Y.; Selloni, A.; Carter, E.A.; Arnold, C.B.; Dankworth, D.C.; Rucker, S.P.; Chelikowsky, J.R.; Yao, N. Breaking a dative bond with mechanical forces. Nat. Commun. 2021, 12, 5635. [CrossRef] [PubMed] 
70. Wadhams, G.H.; Armitage, J.P. Making Sense of It All: Bacterial Chemotaxis. Nat. Rev. Mol. Cell Biol. 2004, 5, 1024-1037. [CrossRef]

71. Janetopoulos, C.; Firtel, R.A. Directional Sensing during Chemotaxis. FEBS Lett. 2008, 582, 2075-2085. [CrossRef]

72. Ikeya, N.; Woodward, J.R. Cellular autofluorescence is magnetic field sensitive. Proc. Natl. Acad. Sci. USA 2021, 118, e2018043118. [CrossRef]

73. Förster, D.; Helmbrecht, T.O.; Mearns, D.S.; Jordan, L.; Mokayes, N.; Baier, H. Retinotectal circuitry of larval zebrafish is adapted to detection and pursuit of prey. Elife 2020, 9, e58596. [CrossRef]

74. De Corte, B.J.; Navarro, V.M.; Wasserman, E.A. Non-cortical magnitude coding of space and time by pigeons. Curr. Biol. 2017, 27, R1264-R1265. [CrossRef] [PubMed]

75. Schnell, A.K.; Loconsole, M.; Garcia-Pelegrin, E.; Wilkins, C.; Clayton, N.S. Jays are sensitive to cognitive illusions. R. Soc. Open Sci. 2021, 8, 202358. [CrossRef]

76. Giannoni-Guzmán, M.A.; Rivera, E.; Aleman-Rios, J.; Melendez Moreno, A.M.; Ramos, M.P.; Pérez-Claudio, E.; Loubriel, D.; Moore, D.; Giray, T.; Agosto-Rivera, J.L. The Role of Colony Temperature in the Entrainment of Circadian Rhythms of Honey Bee Foragers. Ann. Entomol. Soc. Am. 2021, 114, 596-605. [CrossRef] [PubMed]

77. Mareschal, D.; Quinn, P.C. Categorization in Infancy. Trends Cogn. Sci. 2001, 5, 443-450. [CrossRef]

78. Ashby, F.G.; Ell, S.W.; Waldron, E.M. Procedural Learning in Perceptual Categorization. Mem. Cogn. 2003, 31, 1114-1125. [CrossRef] [PubMed]

79. Sloutsky, V.M. The role of similarity in the development of categorization. Trends Cogn. Sci. 2003, 7, 246-251. [CrossRef]

80. Lewis, M.; Balamurugan, A.; Zheng, B.; Lupyan, G. Characterizing Variability in Shared Meaning through Millions of Sketches. In Proceedings of the Annual Meeting of the Cognitive Science Society, Vienna, Austria, 3 February 2021.

81. Lewandowsky, S.; Roberts, L.; Yang, L.X. Knowledge Partitioning in Categorization: Boundary Conditions. Mem Cognit. 2006, 34, 1676-1688. [CrossRef] [PubMed]

82. Sperry, R.W. Cerebral Organization and Behavior: The split brain behaves in many respects like two separate brains, providing new research possibilities. Science 1961, 133, 1749-1757. [CrossRef]

83. Lupyan, G. The conceptual grouping effect: Categories matter (and named categories matter more). Cognition 2008, 108, 566-577. [CrossRef]

84. van Dijk, J.; Kerkhofs, R.; van Rooij, I.; Haselager, P. Special Section: Can There Be Such a Thing as Embodied Embedded Cognitive Neuroscience? Theory Psychol. 2008, 18, 297-316. [CrossRef]

85. Mahon, B.Z.; Caramazza, A. Concepts and categories: A cognitive neuropsychological perspective. Annu. Rev. Psychol. 2009, 60, 27-51. [CrossRef]

86. Cira, N.J.; Benusiglio, A.; Prakash, M. Vapour-Mediated Sensing and Motility in Two-Component Droplets. Nature 2015, 519, 446-450. [CrossRef]

87. Tweedy, L.; Thomason, P.A.; Paschke, P.I.; Martin, K.; Machesky, L.M.; Zagnoni, M.; Insall, R.H. Seeing around corners: Cells solve mazes and respond at a distance using attractant breakdown. Science 2020, 369, eaay9792. [CrossRef]

88. Blackiston, D.; Lederer, E.; Kriegman, S.; Garnier, S.; Bongard, J.; Levin, M. A cellular platform for the development of synthetic living machines. Sci. Robot 2021, 6, eabf1571. [CrossRef]

89. Tarrant, M.; Calitri, R.; Weston, D. Social identification structures the effects of perspective taking. Psychol. Sci. 2012, 23, 973-978. [CrossRef] [PubMed]

90. Takaoka, A.; Maeda, T.; Hori, Y.; Fujita, K. Do dogs follow behavioral cues from an unreliable human? Anim. Cogn. 2015, 18, 475-483. [CrossRef] [PubMed]

91. Havy, M.; Waxman, S.R. Naming influences 9-month-olds' identification of discrete categories along a perceptual continuum. Cognition 2016, 156, 41-51. [CrossRef]

92. Mischel, W.; Ebbesen, E.B. Attention in delay of gratification. J. Pers. Soc. Psychol. 1970, 16, 329-337. [CrossRef]

93. Schnell, A.K.; Boeckle, M.; Rivera, M.; Clayton, N.S.; Hanlon, R.T. Cuttlefish exert self-control in a delay of gratification task. Proc. Biol. Sci. 2021, 288, 20203161. [CrossRef]

94. Boisseau, R.P.; Vogel, D.; Dussutour, A. Habituation in non-neural organisms: Evidence from slime moulds. Proc. Biol. Sci. 2016, 283. [CrossRef]

95. Cabrera, D.; Cabrera, L.; Powers, E. A Unifying Theory of Systems Thinking with Psychosocial Applications. Syst. Res. 2015, 32, 534-545. [CrossRef]

96. Simon, H.A. The Architecture of Complexity. Am. Philos. Soc. 1962, 106, 467-482.

97. Anderson, J.R. The Adaptive Nature of Human Categorization. Psychol Rev. 1991, 98, 409-429. [CrossRef]

98. di Pellegrino, G. Categorization in single neurons. Trends Cogn. Sci. 2001, 5, 186. [CrossRef]

99. Muehlhaus, J.; Heim, S.; Altenbach, F.; Chatterjee, A.; Habel, U.; Sass, K. Deeper insights into semantic relations: An fMRI study of part-whole and functional associations. Brain Lang. 2014, 129, 30-42. [CrossRef] [PubMed]

100. Montoro, P.R.; Luna, D.; Ortells, J.J. Subliminal Gestalt grouping: Evidence of perceptual grouping by proximity and similarity in absence of conscious perception. Conscious. Cogn. 2014, 25, 1-8. [CrossRef] [PubMed]

101. Baron-Cohen, S.; Ashwin, E.; Ashwin, C.; Tavassoli, T.; Chakrabarti, B. Talent in autism: Hyper-systemizing, hyper-attention to detail and sensory hypersensitivity. Philos. Trans. R. Soc. Lond. B Biol. Sci. 2009, 364, 1377-1383. [CrossRef] [PubMed]

102. Lewin, K. Dynamic Theory of Personality; Read Books Ltd.: Redditch, UK, 1935. 
103. Mooney. Perception, Language, and the Part-Whole Problem; Ohio State University: Columbus, OH, USA, 1951.

104. Ackoff, R.L. Towards a System of Systems Concepts. Manag. Sci. 1971, 17, 661-671. [CrossRef]

105. Solomon, K.O.; Medin, D.L.; Lynch, E. Concepts do More than Categorize. Trends Cogn. Sci. 1999, 3, 99-105. [CrossRef]

106. Tversky, B.; Hemenway, K. Objects, Parts, and Categories. J. Exp. Psychol. Gen. 1984, 113, 169-197. [CrossRef]

107. Glushko, R.J.; Maglio, P.P.; Matlock, T.; Barsalou, L.W. Categorization in the wild. Trends Cogn. Sci. 2008, 12, 129-135. [CrossRef]

108. Liberman, Z.; Woodward, A.L.; Kinzler, K.D. The Origins of Social Categorization. Trends Cogn. Sci. 2017, 21, 556-568. [CrossRef]

109. Fisher, M.; Keil, F.C. The Binary Bias: A Systematic Distortion in the Integration of Information. Psychol. Sci. 2018, 29, 1846-1858. [CrossRef]

110. Kominsky, J.F.; Strickland, B.; Wertz, A.E.; Elsner, C.; Wynn, K.; Keil, F.C. Categories and Constraints in Causal Perception. Psychol. Sci. 2017, 28, 1649-1662. [CrossRef]

111. Weily, J. Review of Cybernetics or Control and Communication in the Animal and the Machine. Psychol. Bull. 1949, 46, $236-237$. [CrossRef]

112. Wiener, N. Cybernetics or Control and Communication in the Animal and the Machine; MIT Press: Cambridge, MA, USA, 1961.

113. Clement, C.A.; Falmagne, R.J. Logical Reasoning, World Knowledge, and mental Imagery: Interconnections in Cognitive Processes. Mem. Cogn. 1986, 14, 299-307. [CrossRef]

114. Gopnik, A.; Glymour, C.; Sobel, D.M.; Schulz, L.E.; Kushnir, T.; Danks, D. A theory of causal learning in children: Causal maps and Bayes nets. Psychol. Rev. 2004, 111, 3-32. [CrossRef]

115. Schulz, L.E.; Gopnik, A. Causal learning across domains. Dev. Psychol. 2004, 40, 162-176. [CrossRef]

116. Greene, A.J. Making Connections. Sci. Am. Mind 2010, 21, 22-29. [CrossRef]

117. Piao, Y.; Yao, G.; Jiang, H.; Huang, S.; Huang, F.; Tang, Y.; Liu, Y.; Chen, Q. Do pit vipers assess their venom? Defensive tactics of Deinagkistrodon acutus shift with changed venom reserve. Toxicon 2021, 199, 101-108. [CrossRef] [PubMed]

118. Chersi, F.; Ferro, M.; Pezzulo, G.; Pirrelli, V. Topological self-organization and prediction learning support both action and lexical chains in the brain. Top. Cogn. Sci. 2014, 6, 476-491. [CrossRef]

119. Ferry, A.L.; Hespos, S.J.; Gentner, D. Prelinguistic Relational Concepts: Investigating Analogical Processing in Infants. Child Dev. 2015, 86, 1386-1405. [CrossRef]

120. Harris, P.L.; German, T.; Mills, P. Children's Use of Counterfactual Thinking in Causal Reasoning. Cognition 1996, 61, 233-259. [CrossRef]

121. Mascalzoni, E.; Regolin, L.; Vallortigara, G.; Simion, F. The cradle of causal reasoning: Newborns' preference for physical causality. Dev. Sci. 2013, 16, 327-335. [CrossRef]

122. Rolfs, M.; Dambacher, M.; Cavanagh, P. Visual adaptation of the perception of causality. Curr. Biol. 2013, 23, 250-254. [CrossRef]

123. Dhamala, M. What is the nature of causality in the brain?-Inherently probabilistic: Comment on "Foundational perspectives on causality in large-scale brain networks" by M. Mannino and S.L. Bressler. Phys. Life Rev. 2015, 15, 139-140. [CrossRef] [PubMed]

124. Sanefuji, W.; Haryu, E. Preschoolers' Development of Theory of Mind: The Contribution of Understanding Psychological Causality in Stories. Front. Psychol. 2018, 9, 955. [CrossRef] [PubMed]

125. Marvin. The Early Development of Conceptual Perspective Taking: Distinguishing among Multiple Perspectives. Child Dev. 1976, 47, 511-514. [CrossRef]

126. Premack, D.; Woodruff, G. Does the chimpanzee have a theory of mind? Behav. Brain Sci. 1978, 1, 515-526. [CrossRef]

127. Endler, J.A. Bowerbirds, art and aesthetics: Are bowerbirds artists and do they have an aesthetic sense? Commun. Integr. Biol. 2012, 5, 281-283. [CrossRef]

128. Bugnyar, T.; Reber, S.A.; Buckner, C. Ravens attribute visual access to unseen competitors. Nat. Commun. 2016, 7, 10506. [CrossRef]

129. Chamovitz, D. What a Plant Knows: A Field Guide to the Senses; Scientific American/Farrar, Straus and Giroux: New York, NY, USA, 2012.

130. Montesinos-Navarro, A.; Storer, I.; Perez-Barrales, R. Benefits for nurse and facilitated plants emerge when interactions are considered along the entire life-span. Perspect. Plant Ecol. Evol. Syst. 2019, 41, 125483. [CrossRef]

131. Baron-Cohen, S.; Leslie, A.M.; Frith, U. Does the Autistic Child Have a "Theory of Mind"? Cognition 1985, 21, 37-46. [CrossRef]

132. Vallar, G.; Lobel, E.; Galati, G.; Berthoz, A.; Pizzamiglio, L.; Le Bihan, D. A fronto-parietal system for computing the egocentric spatial frame of reference in humans. Exp. Brain Res. 1999, 124, 281-286. [CrossRef]

133. Dyson, F. Disturbing the Universe; Basic Books: New York, NY, USA, 1979.

134. Zwick, A.; Álvarez, G.A.; Kurizki, G. Maximizing Information on the Environment by Dynamically Controlled Qubit Probes. Phys. Rev. Appl. 2016, 5, 014007. [CrossRef]

135. Álvarez, G.A. Personal Correspondence, Email To Cabrera: "RE: Question about Your Article on Qubit Probes". 2021. Available online: https:/ / tinyurl.com/4876tv64 (accessed on 1 December 2021).

136. Ruby, P.; Decety, J. How would you feel versus how do you think she would feel? A neuroimaging study of perspective-taking with social emotions. J. Cogn. Neurosci. 2004, 16, 988-999. [CrossRef]

137. Russell, J.; Alexis, D.; Clayton, N. Episodic future thinking in 3- to 5-year-old children: The ability to think of what will be needed from a different point of view. Cognition 2010, 114, 56-71. [CrossRef]

138. Rakoczy, H.; Wandt, R.; Thomas, S.; Nowak, J.; Kunzmann, U. Theory of mind and wisdom: The development of different forms of perspective-taking in late adulthood. Br. J. Psychol. 2018, 109, 6-24. [CrossRef] 
139. Mafessoni, F.; Lachmann, M. The complexity of understanding others as the evolutionary origin of empathy and emotional contagion. Sci. Rep. 2019, 9, 5794. [CrossRef]

140. Tversky, A.; Kahneman, D. The Framing of Decisions and the Psychology of Choice. Science 1981, 211, 453-458. [CrossRef]

141. Schober. Spatial Perspective-Taking in Conversation. Cognition 1993, 47, 1-24. [CrossRef]

142. Bateson, G. Perspective Taking: Imagining how another would feel versus imagining how you would feel. Personal. Soc. Psychol. Bull. 1997, 23, 751-758. [CrossRef]

143. Knowles, M.L. Social rejection increases perspective taking. J. Exp. Soc. Psychol. 2014, 55, 126-132. [CrossRef]

144. Cavallo, A.; Ansuini, C.; Capozzi, F.; Tversky, B.; Becchio, C. When Far Becomes Near. Psychol. Sci. 2017, 28, 69-79. [CrossRef]

145. Neale, M.A.; Bazerman, M.H. The Role of Perspective-Taking Ability in Negotiating under Different Forms of Arbitration. Ind. Labor. Relat. Rev. 1983, 36, 378-388. [CrossRef]

146. Galinsky, A.D.; Moskowitz, G.B. Perspective-taking: Decreasing stereotype expression, stereotype accessibility, and in-group favoritism. J. Pers. Soc. Psychol. 2000, 78, 708-724. [CrossRef]

147. Takaku, S.; Weiner, B.; Ohbuchi, K.I. A cross-cultural examination of the effects of apology and perspective taking on forgiveness. J. Lang. Soc. Psychol. 2001, 20, 144-166. [CrossRef]

148. Parker, S.K.; Axtell, C.M. Seeing Another Viewpoint: Antecedents and Outcomes of Employee Perspective Taking. Acad. Manag. J. 2001, 44, 1085-1100. [CrossRef]

149. Epley, N.; Keysar, B.; Van Boven, L.; Gilovich, T. Perspective taking as egocentric anchoring and adjustment. J. Pers. Soc. Psychol. 2004, 87, 327-339. [CrossRef]

150. Davis, M.H.; Soderlund, T.; Cole, J.; Gadol, E.; Kute, M.; Myers, M.; Weihing, J. Cognitions associated with attempts to empathize: How do we imagine the perspective of another? Pers. Soc. Psychol. Bull. 2004, 30, 1625-1635. [CrossRef]

151. Harwood, M.D.; Farrar, M.J. Conflicting emotions: The connection between affective perspective taking and theory of mind. Br. J. Dev. Psychol. 2006, 24, 401-418. [CrossRef]

152. Tversky, B.; Hard, B.M. Embodied and disembodied cognition: Spatial perspective-taking. Cognition 2009, 110, 124-129. [CrossRef]

153. Wang, C.S.; Tai, K.; Ku, G.; Galinsky, A.D.; Urgesi, C. Perspective-Taking Increases Willingness to Engage in Intergroup Contact. PLoS ONE 2014, 9, e85681. [CrossRef]

154. Ben-Ami Bartal, I.; Decety, J.; Mason, P. Empathy and pro-social behavior in rats. Science 2011, 334, 1427-1430. [CrossRef]

155. Satoh, S.; Bshary, R.; Shibasaki, M.; Inaba, S.; Sogawa, S.; Hotta, T.; Awata, S.; Kohda, M. Prosocial and antisocial choices in a monogamous cichlid with biparental care. Nat. Commun. 2021, 12, 1775. [CrossRef]

156. Gagliano, M.; Renton, M.; Depczynski, M.; Mancuso, S. Experience teaches plants to learn faster and forget slower in environments where it matters. Oecologia 2014, 175, 63-72. [CrossRef]

157. Gagliano, M. Inside the Vegetal Mind: On the Cognitive Abilities of Plants. In Memory and Learning in Plants; Baluska, F., Gagliano, M., Witzany, G., Eds.; Springer International Publishing: Cham, Switzerland, 2018; pp. 215-220.

158. Stonier, T. Information and the Internal Structure of the Universe: An Exploration into Information Physics; Springer: Berlin/Heidelberg, Germany, 1990.

159. Mingers, J.C. Information and meaning: Foundations for an intersubjective account. Inf. Syst. J. 1995, 5, 285-306. [CrossRef]

160. Weinberg, S. The Quantum Theory of Fields, Volume 1: Foundations, 1st ed.; Cambridge University Press: Cambridge, UK, 2005.

161. Schwartz, M.D. Quantum Field Theory and the Standard Model, 1st ed.; Cambridge University Press: Cambridge, UK, 2013.

162. Simms, J.R. A Measure of Knowledge; Philosophical Library: New York, NY, USA, 1971.

163. Vedral, V. Decoding Reality: The Universe as Quantum Information (Oxford Landmark Science), 2nd ed.; Oxford University Press: Oxford, UK, 2018.

164. Cabrera, D.; Cabrera, L.; Cabrera, E. The 'Fish Tank' Experiments: Metacognitive awareness significantly increases cognitive complexity. Systems 2022, under process.

165. Cabrera, D.; Cabrera, L. Any Person, Any Study: A Different Kind of Theory of Everything (ToE). In Routledge Handbook of Systems Thinking; Cabrera, D., Cabrera, L., Midgley, G., Eds.; Routledge: London, UK, 2022.

166. Mandelbrot, B. How long is the coast of britain? Statistical self-similarity and fractional dimension. Science 1967, 156, 636-638. [CrossRef]

167. West, G.B. Scale: The Universal Laws of Growth, Innovation, Sustainability, and the Pace of Life in Organisms, Cities, Economies, and Companies; Penguin: New York, NY, USA, 2017. 